\title{
More female patients and fewer stimuli per session are associated with the short-term antidepressant properties of repetitive transcranial magnetic stimulation (rTMS): a meta-analysis of 54 sham- controlled studies published between 1997-20I 3
}

This article was published in the following Dove Press journal:

Neuropsychiatric Disease and Treatment

7 May 2014

Number of times this article has been viewed

\author{
Karina Karolina Kedzior' \\ Valeriya Azorina ${ }^{2}$ \\ Sarah Kim Reitz' \\ 'School of Humanities and Social \\ Sciences, ${ }^{2}$ School of Engineering and \\ Science, Jacobs University Bremen, \\ Bremen, Germany
}

Background: Repetitive transcranial magnetic stimulation (rTMS) of the dorsolateral prefrontal cortex (DLPFC) appears to have short-term antidepressant properties. The aim of the current study was to update our previous meta-analysis and to investigate factors associated with the antidepressant properties of rTMS.

Method: Following a systematic literature search conducted in Medline and PsycInfo, N=14 sham-controlled, parallel design studies (published after 2008 to August 2013) that had utilized rTMS of the DLPFC in major depression were included in the current meta-analysis. The sensitivity and moderator analyses also included data from $\mathrm{N}=40$ studies (published in 1997-2008) from our previous meta-analysis. The effect size (Cohen's $d$ ) in each study was the standardized difference in mean depression scores (on Hamilton Depression Rating Scale, Beck Depression Inventory, Montgomery Åsberg Depression Rating Scale) from baseline to final (after last session) in rTMS compared to sham groups.

Results: According to a random-effects model with inverse-variance weights, depression scores were significantly reduced after rTMS compared to sham in studies published from $2008-2013$ based on $\mathrm{N}=659$ patients (overall mean weighted $d=-0.42,95 \%$ confidence interval: $-0.66,-0.18, P=0.001$ ). Combining studies from our past and current meta-analyses (published in 1997-2013; N=54) revealed that depression was significantly reduced after left-fast ( $>1 \mathrm{~Hz})$, right-slow ( $\leq 1 \mathrm{~Hz}$ ), and bilateral (or sequential) rTMS of DLPFC compared to sham. Significant antidepressant properties of rTMS were observed in studies with patients who were treatment resistant, unipolar (or bipolar), non-psychotic, medication-free (or started on antidepressants concurrently with rTMS). According to univariate meta-regressions, depression scores were significantly lower in studies with more female patients and fewer stimuli per session. There was little evidence that publication bias occurred in the analysis.

Conclusion: According to this study, the largest meta-analysis to date, short-term antidepressant properties of rTMS are independent of concurrent antidepressants and might depend on sex and the number of stimuli per session.

Keywords: repetitive transcranial magnetic stimulation (rTMS), depression, sham-controlled, DLPFC, meta-analysis, systematic review

\section{Background}

A large volume of academic publications has been dedicated to the antidepressant properties of repetitive transcranial magnetic stimulation (rTMS) in the treatment of 
major depression. Our search of the Medline and PsycInfo databases identified $\mathrm{N}=963$ sources (duplicates excluded) with terms "rTMS" and "depression" in their titles or subject between (any date to September 2013). A vast majority of these sources are narrative literature reviews largely suggesting that approximately ten sessions of daily rTMS appear to be effective in acute cases of major depression (or major depressive episode) in the short-term (by comparing depression scores before the first versus after the last session of rTMS). However, the exact factors mediating the antidepressant properties of rTMS are still not well understood. According to randomized-controlled trials (RCTs) and open-label studies conducted on mostly unipolar patients, rTMS was more effective in patients who were younger, ${ }^{1,2}$ less treatment-resistant (in the current episode or with less prior treatment failures), ${ }^{1,3-5}$ with a shorter current episode, ${ }^{3,5}$ and without a comorbid anxiety disorder. ${ }^{5}$ Furthermore, extension trials in patients who failed to respond during the short-term, double-blind phases of studies showed that the antidepressant response to rTMS was superior in female patients, ${ }^{5}$ was observed only after longer stimulation periods (such as 4 weeks or more), ${ }^{5,6}$ and required an alteration in the stimulation site and frequency (from left-fast to right-slow rTMS of dorsolateral prefrontal cortex [DLPFC]). ${ }^{6}$

Surprisingly, the antidepressant predictors of rTMS from the primary studies listed above have not been systematically confirmed in the relevant 17 quantitative meta-analyses (published 2001-2013) of the high-quality primary studies (sham-controlled randomized trials). ${ }^{7-23}$ According to the meta-analyses to date, the short-term antidepressant properties were most consistently observed in studies using the fast $(>1 \mathrm{~Hz})$ rTMS of the left DLPFC. ${ }^{22,24}$ The slow $(\leq 1 \mathrm{~Hz})$ rTMS of the left or right DLPFC and bilateral or sequential designs were also effective at reducing depression severity in the short-term but were utilized in only very few primary studies. $14,18,19,21,23$

Similarly to the RCTs, the benefit of longer study designs (with ten or 15 rTMS sessions) in treating depression has already been noted in the earlier meta-analyses. ${ }^{9,12,15}$ However, neither duration of study and other rTMS parameters (frequency of stimulation, motor threshold, stimuli/session, total stimuli) nor mean age of patients were associated with the effect sizes in meta-analyses . ${ }^{8,14,17,19,20,23}$ Furthermore, rTMS was effective in studies with medicated or medication-free patients, ${ }^{11,14,19,22,23}$ as well as in studies with medicationresistant patients..$^{14,16,17,20}$ However, a better outcome was expected with less resistance. ${ }^{8,15}$ Finally, the antidepressant effect of rTMS was higher in studies with non-psychotic patients ${ }^{19}$ but was similar in studies with unipolar versus bipolar patients. ${ }^{20,23}$

One reason for such inconsistent findings is that most past meta-analyses included too few studies to reliably detect any differences in effect sizes based on study characteristics (clinical and/or rTMS parameters). Furthermore, unlike in meta-analyses, predictors of rTMS response were often identified during different (open-label and/or follow-up) phases of primary studies. Finally, meta-analyses were computed based on group data compared to primary studies that had utilized individual patient data.

In an attempt to improve the statistical power of the past analyses, we have conducted a meta-analysis on $\mathrm{N}=40$ sham-controlled studies selected from the past 13 metaanalyses ${ }^{4,7-14,16-19}$ published between 2001 and 2010. A shortterm antidepressant effect of the left-fast rTMS of DLPFC was univariately observed in studies with higher proportions of female patients not controlling for any other study characteristics (clinical and/or properties of rTMS). The antidepressant effect of the left-fast rTMS was also present in studies with patients who were medication-free, unipolar (or bipolar), treatment-resistant and without psychotic features.

The current study had three main aims. Since our previous meta-analysis included primary studies published up to 2008 , the first aim of the current study was to update our results by conducting a new meta-analysis of the short-term effects of rTMS in depression in studies published after 2008 until August 2013. These "new" studies were located using a novel systematic literature search in contrast to the $\mathrm{N}=40$ "old" studies in our previous meta-analysis that were selected from the past 13 meta-analyses published in 2001-2010. Thus, the second aim of the current study was to compare the overall mean weighted effect sizes of the "old" studies with the "new" studies due to the different methods of searching for primary studies utilized in the two metaanalyses. Furthermore, our previous meta-analysis focused on the characteristics of studies that had utilized only the left-fast rTMS of DLPFC. Thus, the third aim of the current analysis was to find out if any patient characteristics or rTMS parameters would be associated with the short-term antidepressant properties of rTMS in all "new" and "old" sham-controlled studies published between September 1997 and August 2013. The reason for combining all studies was to improve the statistical power of all statistical (moderator and subgroup) analyses.

Based on our and other past meta-analyses, it was hypothesized that depression would be reduced following the active rTMS compared to sham in the "new" studies (those after 
2008). It was expected that such an antidepressant effect would be higher in the "new" compared to the "old" studies if the quality of the more recent studies has improved due to more advanced stimulators and better established parameters of rTMS. Based on our past meta-analysis of the left-fast rTMS studies, it was expected that, when combining all studies regardless of rTMS parameters, depression scores would be significantly reduced in studies with higher proportions of female patients. We also expected that, based on results from primary studies, the antidepressant properties of rTMS could be related to other patient characteristics and/or rTMS parameters if the statistical power of such comparisons were improved by adding the "new" studies to the "old" ones.

\section{Methods}

\section{Systematic literature search and study selection}

The details of the systematic literature search are shown in Table 1. A "control search" was first conducted in the PsycInfo and Medline databases for $\mathrm{N}=40$ studies published between 1995 and 2008 that were included in our previous meta-analysis. These $\mathrm{N}=40$ studies were obtained from the past 13 meta-analyses (published 2001-2010) rather than from a systematic literature search (Table $\mathrm{S} 1$ ). Since all $\mathrm{N}=40$ studies were located during the control search, we concluded that these two databases were adequate for performing the current literature search for studies published in (any month of) 2008 until August 2013.

The results of the systematic literature search and the study selection procedure are summarized in the PRISMA flowchart (Figure 1). ${ }^{25}$ Following the exclusion of irrelevant studies (based on titles and abstracts), $\mathrm{N}=50$ primary studies were assessed in full-length (Figure 1 and Table S2). A total of $\mathrm{N}=18$ out of 50 "new" studies (published 2010-2013) located during our systematic search met the inclusion criteria for the current analysis (none of the studies published in 2009 met the inclusion criteria). Most studies were excluded because they were not sham-controlled or contained data published in other studies already included in the current analysis (other exclusion criteria are listed in Figure 1). The inclusion criteria for the current meta-analysis were:

1. sham-controlled parallel design;

2. major depressive disorder or episode diagnosed according to the Diagnostic and Statistical Manual of Mental Disorders (DSM-IV) or International Statistical Classification of Diseases and Related Health Problems (ICD-10) criteria;

3. depression severity assessed using any version of a standardized scale (Hamilton Depression Rating Scale (HAMD), ${ }^{26}$ Beck Depression Inventory (BDI), ${ }^{27}$ and Montgomery Åsberg Depression Rating Scale $\left(\mathrm{MADRS}^{28}\right)$ );

4. and active rTMS and sham administered at the same location of DLPFC (left, right, or bilateral).

As explained in the Results section, four of the 18 "new" studies were identified as outliers and removed from all analyses. Thus, the current meta-analysis was performed on $\mathrm{N}=14$ "new" studies. To improve the power of comparisons, the sensitivity analyses also included data from $\mathrm{N}=40$ "old" studies (published in 1997-2008) from our previous metaanalysis (Table S1).

Table I Details of the systematic search strategy (all searches were performed in English with no language restrictions)

\begin{tabular}{|c|c|c|}
\hline Search & Search terms & Databases (time frame) \\
\hline $\begin{array}{l}\text { Search I } \\
N=821\end{array}$ & $\begin{array}{l}\text { [TI or SU ("transcranial magnetic stimulation" or "trans- cranial magnetic } \\
\text { stimulation" or "repetitive transcranial magnetic stimulation" or "repetitive } \\
\text { trans- cranial magnetic stimulation" or TMS or rTMS)] AND [TI or SU } \\
\text { (depress* or dysthy* or MDD or cyclothym* or bipolar or "mani*- depress*")] }\end{array}$ & $\begin{array}{l}\text { Psyclnfo and Medline } \\
\text { (any date - 2008) }\end{array}$ \\
\hline $\begin{array}{l}\text { Search } 2 \\
N=584^{a}\end{array}$ & $\begin{array}{l}\text { [TI or SU ("transcranial magnetic stimulation" or "trans- cranial magnetic } \\
\text { stimulation" or "repetitive transcranial magnetic stimulation" or "repetitive } \\
\text { trans- cranial magnetic stimulation" or TMS or rTMS)] AND [TI or SU } \\
\text { (depress* or dysthy* or MDD or cyclothym* or bipolar or "mani*- depress*")] }\end{array}$ & $\begin{array}{l}\text { EBSCO Psyclnfo and Medline } \\
\text { (2008 - August 2013) }\end{array}$ \\
\hline $\begin{array}{l}\text { Search } 3 \\
N=128^{a}\end{array}$ & $\begin{array}{l}\text { [Title, Abstract, Keywords ("transcranial magnetic stimulation" or "trans- } \\
\text { cranial magnetic stimulation" or "repetitive transcranial magnetic stimulation" } \\
\text { or "repetitive trans- cranial magnetic stimulation" or TMS or rTMS)] AND } \\
\text { [Title, Abstract, Keywords (depress* or dysthy* or MDD or cyclothym* or } \\
\text { bipolar or "mani*- depress*”)] }\end{array}$ & $\begin{array}{l}\text { Cochrane Library (Category } \\
\text { searched: Trials) } \\
\text { (2008 - August 2013) }\end{array}$ \\
\hline
\end{tabular}

Notes: Search I was a "control search" to find out if the N=40 studies included in the past I 3 meta-analyses (published in 200I-20I0) could be located using two databases only. Since the search detected all these resources, Search 2 was conducted on Psyclnfo and Medline that appeared to have an adequate coverage of studies in this area. Search 3 of the Cochrane library did not identify any additional studies than Search 2. ${ }^{2}$ Duplicates excluded within search.

Abbreviations: MDD, major depressive disorder; N, number of sources; rTMS, repetitive transcranial magnetic stimulation; SU, subject; TI, title. 


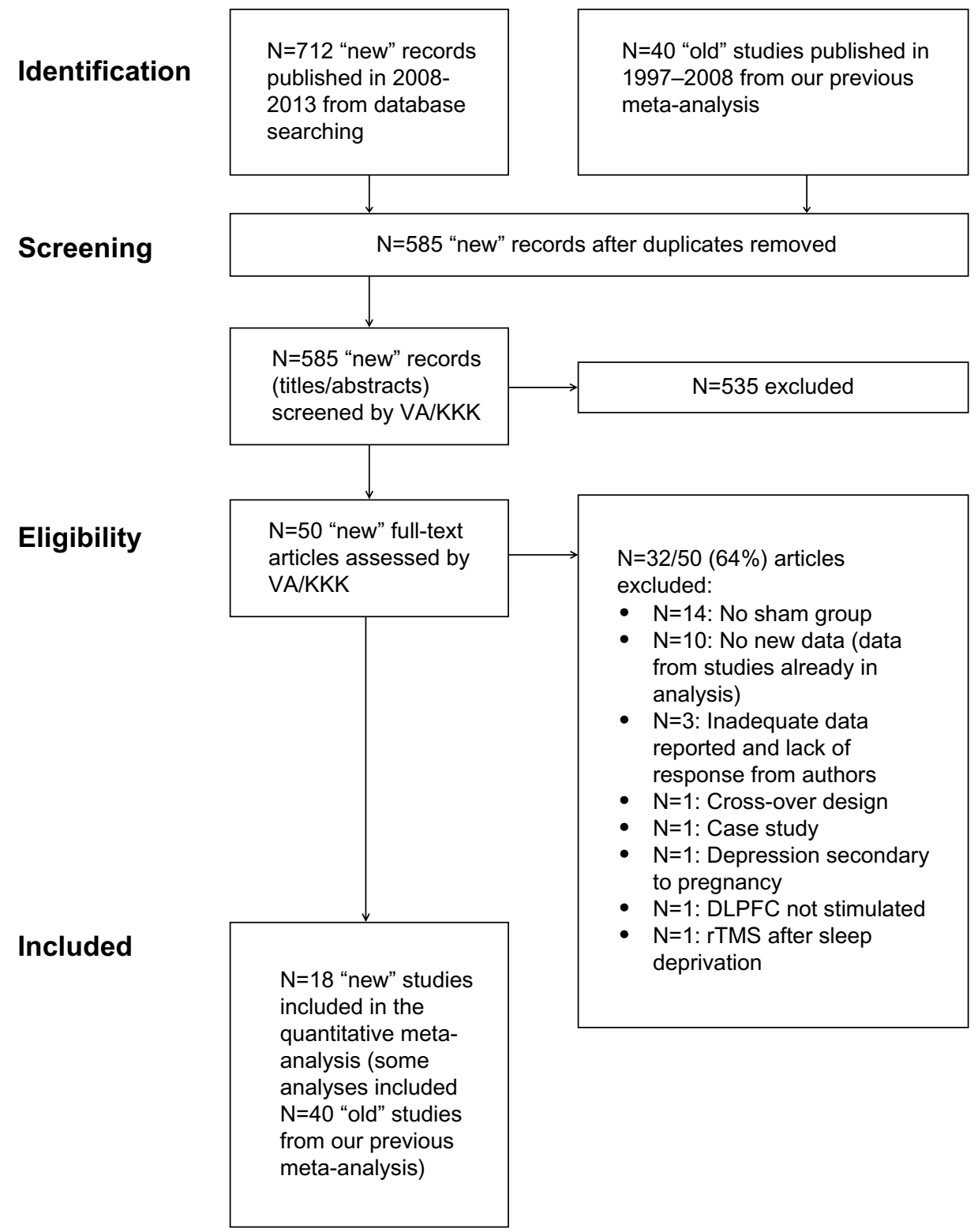

Figure I Study assessment and exclusionary criteria.

Abbreviations: DLPFC, dorsolateral prefrontal cortex; rTMS, repetitive transcranial magnetic stimulation.

\section{Data extraction}

Data were extracted from all $\mathrm{N}=18$ studies by two authors (VA and KKK) independently and any inconsistencies were resolved (there were no major inconsistencies requiring additional experts' opinion). The rTMS parameters are shown in Table 2, and the clinical and demographic characteristics of patients are shown in Table 3.

\section{Meta-analysis}

The mathematical approach used in the current meta-analysis is based on the method of Hedges et al. ${ }^{29}$ The mean depression scores at baseline as well as after the last session (final) in the sham and the active rTMS groups in each study are listed in Table 3. The mean (M) and standard deviations (SD) of depression scores in the sham and the active rTMS groups were computed for each group separately in SPSS version 21 (IBM Corporation, Armonk, NY, USA) using the difference score (depression score at baseline - final). These difference scores and their SD are shown in the last two columns of Table 3. Multiple independent subgroups of patients were combined into one active rTMS and one sham group per scale and per study to comply with the assumption of meta-analysis that each study should contribute only one effect size to the overall 


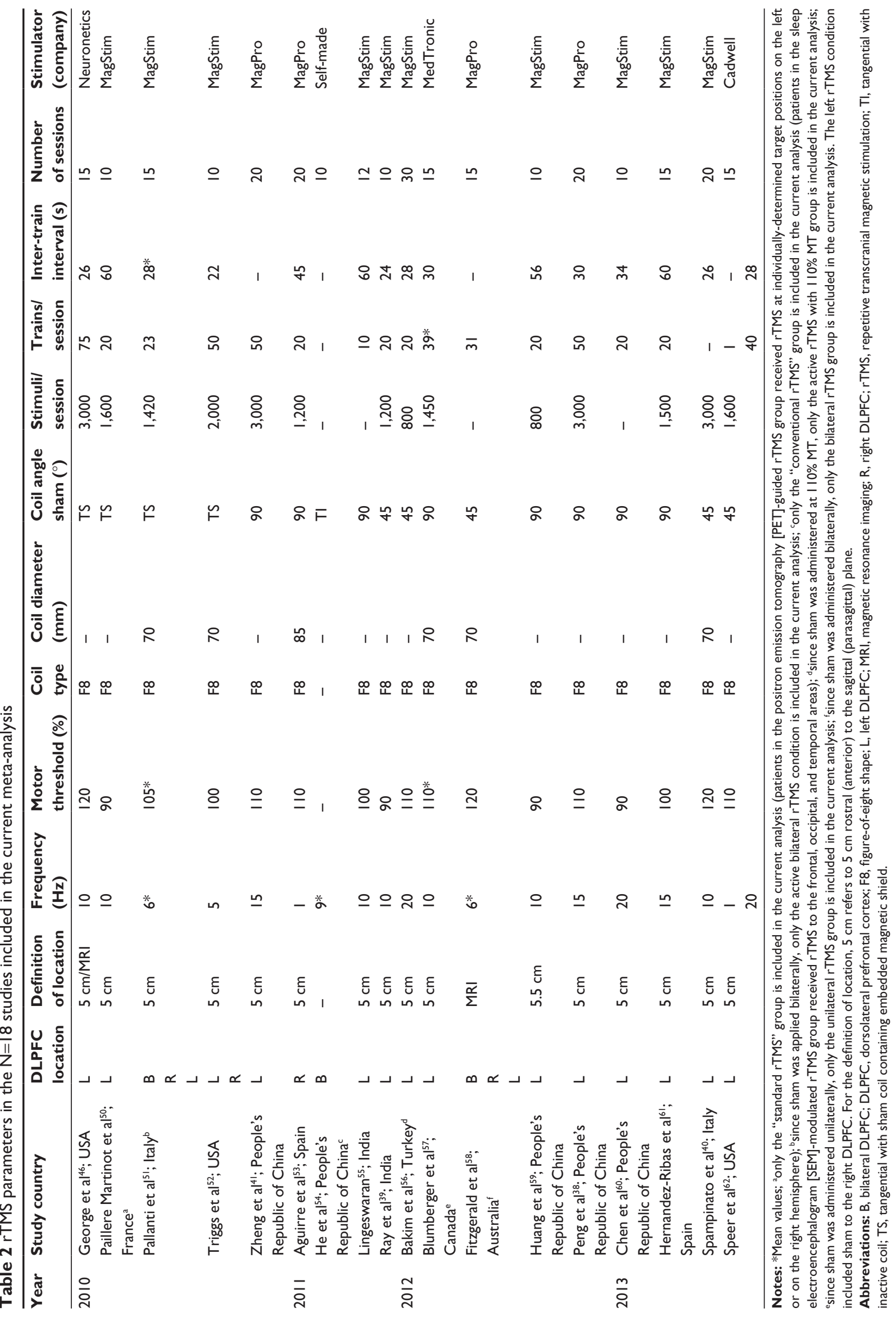




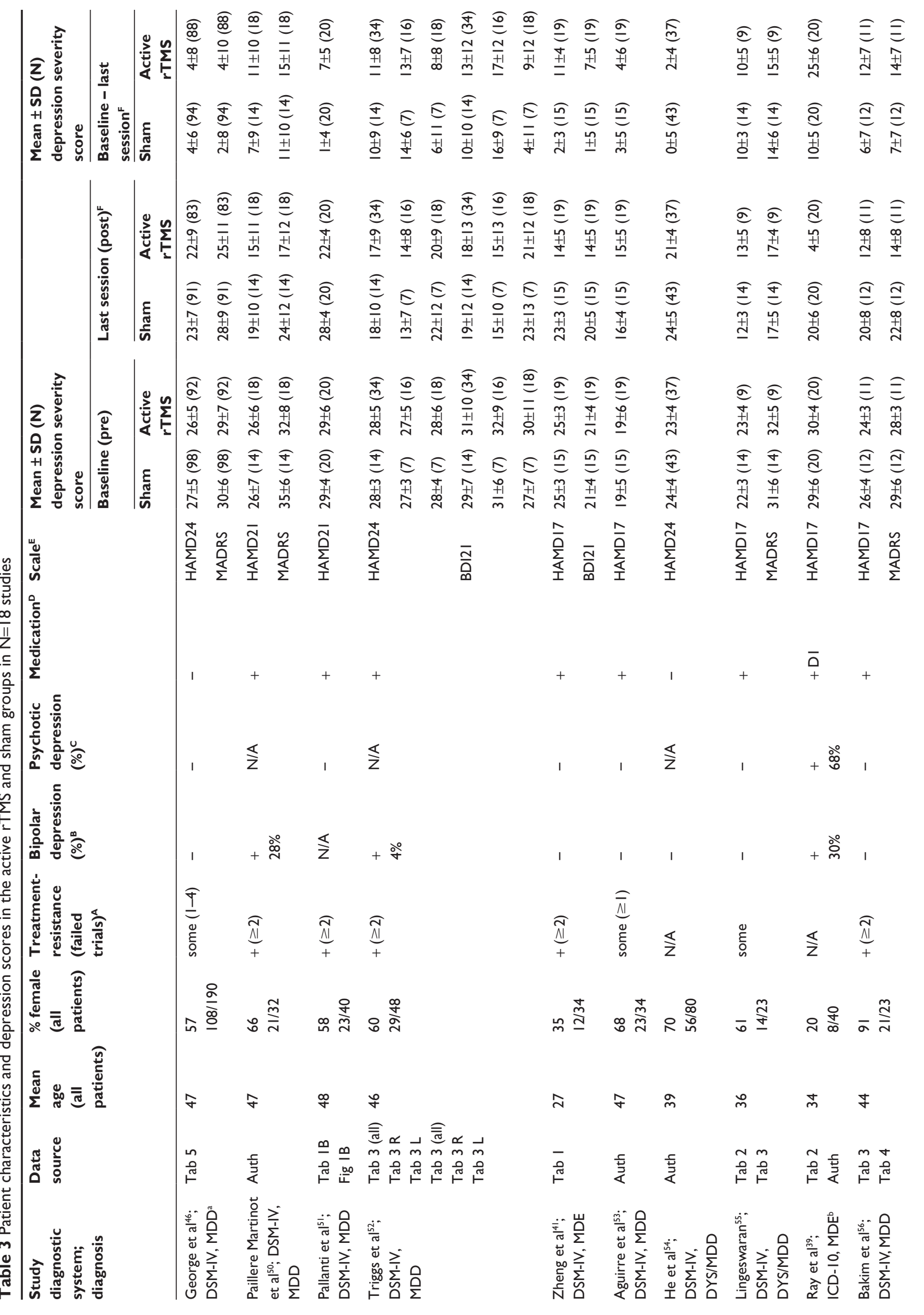




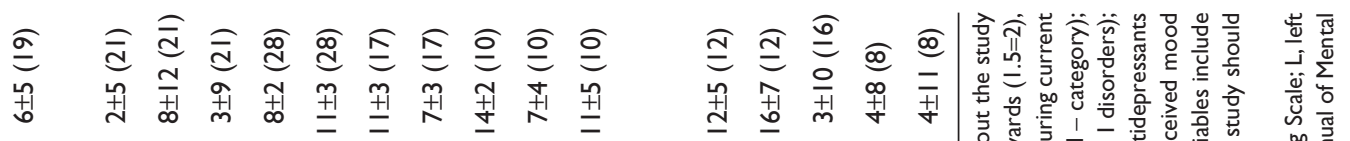

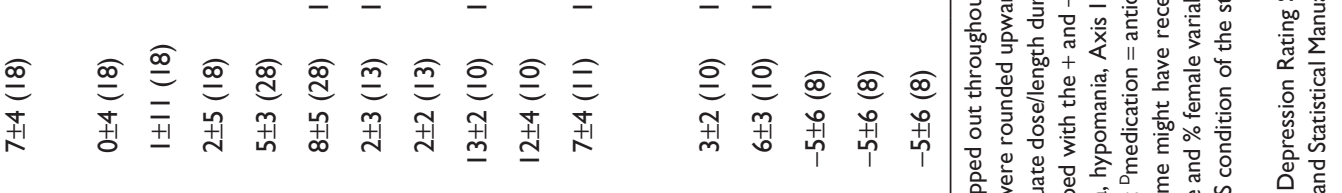

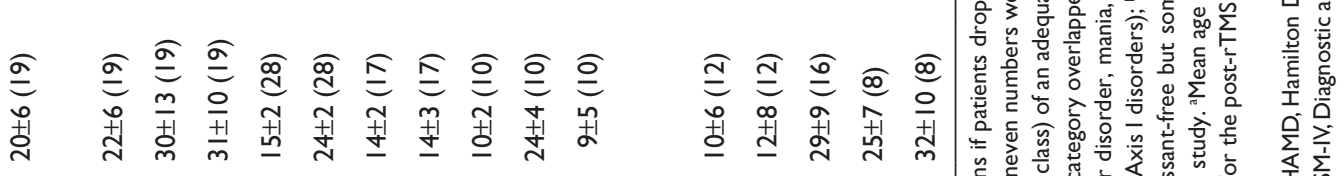

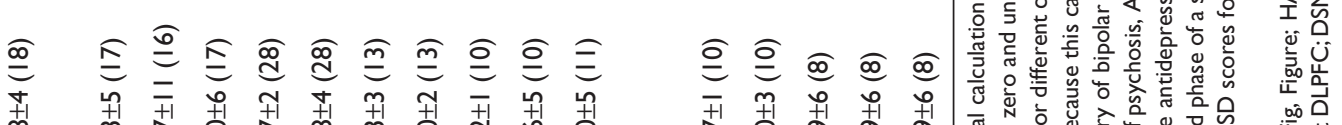

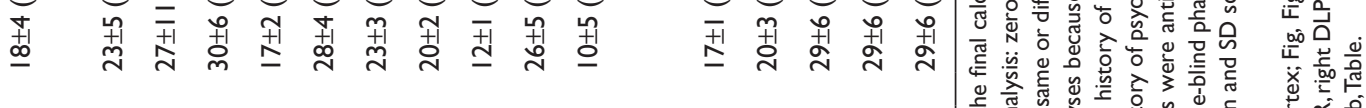

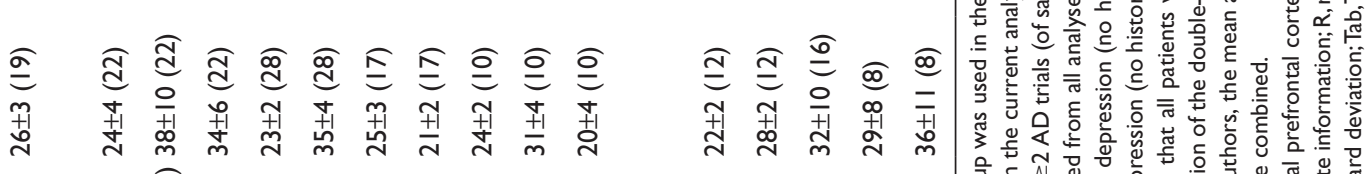

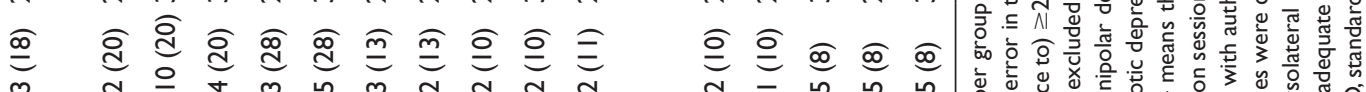

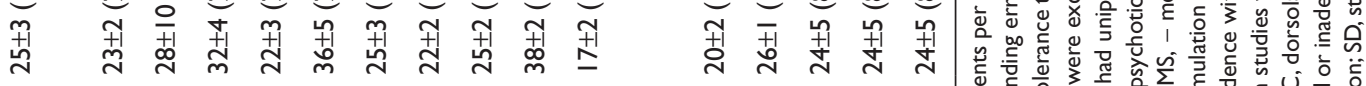

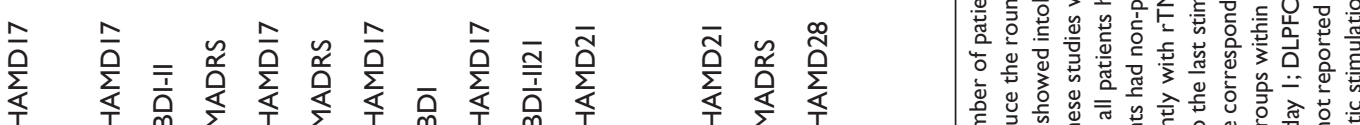

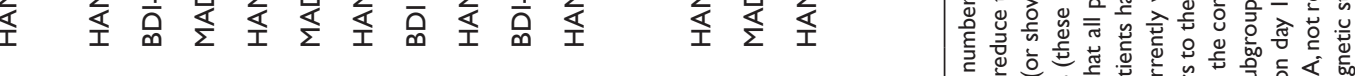

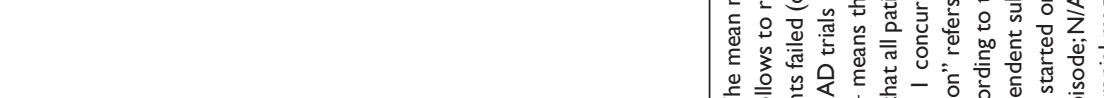

$+\quad+\quad \overline{0}+\quad+\quad+\quad+$

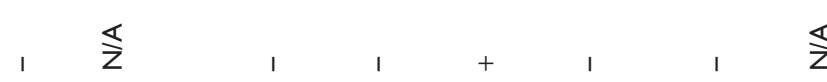

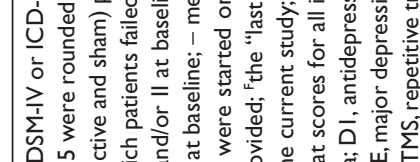

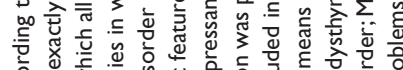

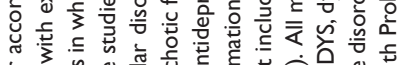

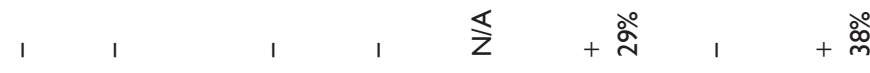

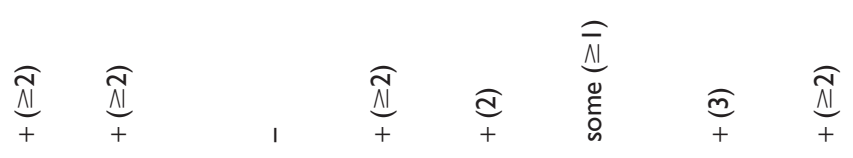

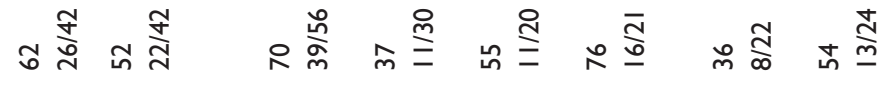

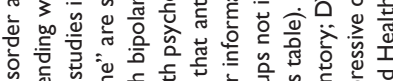

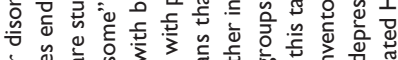

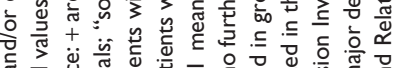

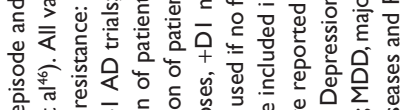

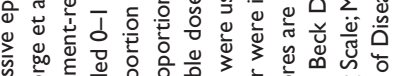

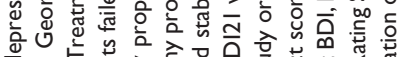

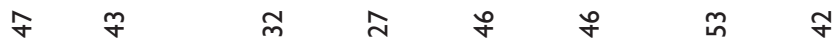

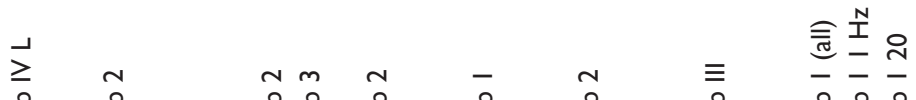

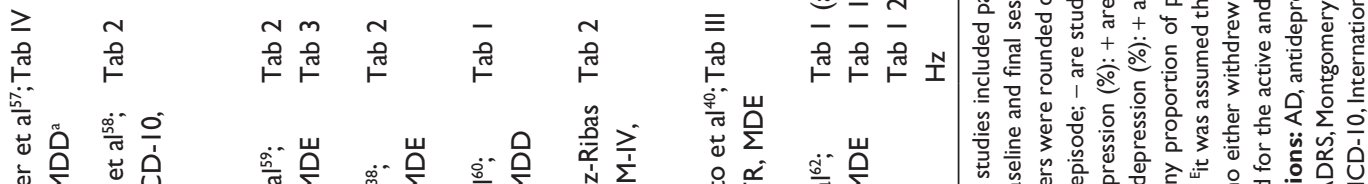

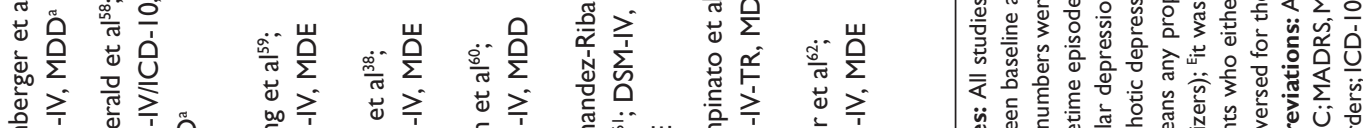

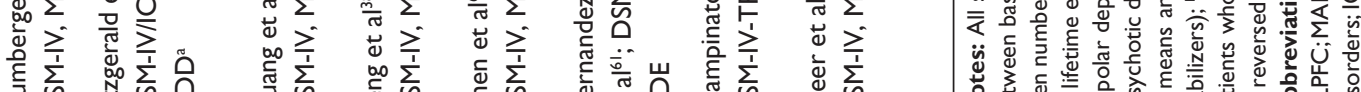

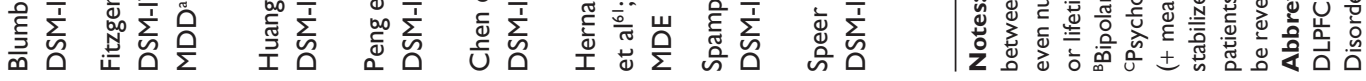


analysis. These combined scores appear in rows labelled "all" in Table 3.

The meta-analysis was computed using Comprehensive Meta-Analysis 2.0 (CMA; Biostat Inc., Englewood, NJ, USA). If one study utilized multiple depression scales then multiple effect sizes based on each scale were computed; these effect sizes were combined into one effect size per study using an arithmetic mean. The effect size used in the current analysis was the standardized mean difference (Cohen's $d$ ) between depression scores at baseline to final after sham compared to active rTMS. The interpretation criteria for the absolute size of Cohen's $d$ are: $d=0.20-0.49$ (small), $d=0.50-0.79$ (moderate), and $d \geq 0.80$ (large). ${ }^{30}$

The current study utilized the random-effects model of meta-analysis ${ }^{29}$ with the inverse-variance weights (a sum of the within- and between-study variance). ${ }^{31}$ The overall mean weighted effect size $d$ of all studies was the sum of the product of all effect sizes and weights divided by the sum of all weights. ${ }^{29}$ Negative values of $d$ indicated that rTMS had antidepressant properties compared to sham.

The heterogeneity among the effect sizes was investigated using a $Q$ statistic and an $I^{2}$ index $\left(I^{2}=100 \% \times(Q-d f) / Q\right.$ with $d f=k-1 ; k=$ number of studies). ${ }^{29}$ The $I^{2}$ index shows the variability in effect sizes due to real (rather than chance) differences among studies and can be interpreted using the following criteria: $25 \%$ (little heterogeneity due to real differences among studies), 50\% (moderate heterogeneity), and $75 \%$ (high heterogeneity). ${ }^{32}$

\section{Sensitivity and moderator analyses}

The stability of the overall mean weighted $d$ over time was investigated as one study at a time was added to all previous studies (cumulative analysis) and as one study at a time was removed from the overall analysis (one study removed analysis). The moderator analyses (subgroup analyses and univariate meta-regressions) were used to test the influence of systematic differences among studies (clinical characteristics or patients and rTMS parameters) on the overall mean weighted $d$.

\section{Publication bias analyses}

Publication bias was assessed using methods available in CMA (Biostat). The Rosenthal's Fail-Safe $\mathrm{N}^{33}$ was computed to find out the number of studies (theoretically missing from the current analysis) required to lower the overall mean weighted $d$ to zero in the current analysis.
The Duval and Tweedie's Trim-and-Fill analysis ${ }^{34}$ was used to test if the so-called funnel plot of $d$ versus standard error of the mean (SEM)/study ${ }^{35}$ was symmetrical around the overall mean weighted $d$ of all studies. Finally, the Begg and Mazumdar Rank Order Correlation (Kendall's tau $b$ ) between the standardized $d$ versus SEM in each study, ${ }^{36}$ and the Egger's regression of 1/SEM (predictor) on the standardized $d,{ }^{37}$ were used to test whether smaller studies differ systematically (significantly) from the larger studies. It was assumed that publication bias might be present if the Fail-Safe $\mathrm{N}$ is low, the funnel plot is asymmetrical, Begg and Mazumdar Correlation is statistically significant, and/or the intercept of the regression line significantly deviates from zero, causing an asymmetry of the funnel plot. $^{29}$

\section{Results}

An inspection of the weighted effect sizes $d$ for each of the $\mathrm{N}=58$ studies revealed that $\mathrm{N}=4$ studies (all "new" studies $)^{38-41}$ were outliers in the current analysis. Specifically, weighted $d$ s in these studies were statistically significantly higher than the overall mean weighted $d$ of all other studies (Figures S1 and S2). As a consequence, the overall mean weighted $d$ was inflated when these studies were included in the meta-analysis of the $\mathrm{N}=18$ "new" studies $(d=-0.80)$ compared to when these studies were removed from the analysis $(\mathrm{N}=14$ "new" studies: $d=-0.42$; Table 4). Thus, these $\mathrm{N}=4$ "new" studies were excluded and all subsequent analyses were computed using $\mathrm{N}=14$ "new" studies.

One of the four studies ${ }^{39}$ might have been an outlier because of the following methodological differences between this and all other studies: the use of a clinical interview for HAMD scale (rather than HAMD scale alone), depression diagnosed using ICD-10 (rather than DSM-IV), inclusion of high proportions of patients with bipolar (30\%) and psychotic depression (68\%; Table 3 ). The reasons why the other three studies might have been outliers are addressed in the Discussion section.

The N=14 "new" studies were conducted in nine countries (three each in the US and People's Republic of China; two in Spain; one each in France, Italy, Turkey, India, Canada, and Australia; Table 2). These studies were conducted on a total of $\mathrm{N}=659$ patients in the active rTMS $(\mathrm{N}=340)$ and sham $(\mathrm{N}=319)$ groups. All patients had diagnoses of a major depressive episode and/or disorder according to DSM-IV or ICD-10 (Table 3). There was little evidence that the 
Table 4 Results of the random-effects meta-analysis of the $\mathrm{N}=14$ "new" studies (20 I0-20I3) and all N=54 studies: $\mathrm{N}=40$ "old" studies (1997-2008) and N=14 “new” studies

\begin{tabular}{|c|c|c|c|}
\hline & $\mathbf{N}$ studies (\%) & $d(95 \% \mathrm{Cl})$ & $\boldsymbol{P}_{\text {two-tailed }}$ \\
\hline \multicolumn{4}{|l|}{ Overall mean weighted $d$} \\
\hline “old 40” studies (1997-2008) & 40 & $-0.54(-0.68,-0.4 \mathrm{I})$ & $<0.00 I^{*}$ \\
\hline “new I8" studies (20I0-20I3) & 18 & $-0.80(-1.16,-0.44)$ & $<0.00 I^{*}$ \\
\hline "new 14" studies, outliers excluded & 14 & $-0.42(-0.66,-0.18)$ & $<0.00 I^{*}$ \\
\hline “old 40" versus "new 14 " studies & & & 0.151 \\
\hline “New" N=14 studies & $2010-2013$ & & \\
\hline Total $\mathrm{N}$ patients & rTMS/sham & $659(340 / 319)$ & \\
\hline Heterogeneity & $Q(d f) ; P_{\text {two-tailed }} ; P^{2}$ & $\begin{array}{l}Q(d f \mid 3)=25.9 \\
P=0.018^{*} ; P^{2}=50 \%\end{array}$ & \\
\hline Rosenthal's Fail-safe $N$ for $P>0.05$ & $\begin{array}{l}\mathrm{N} \text {-studies needed to reduce the } \\
\text { overall mean weighted } d \text { to } 0\end{array}$ & $\begin{array}{l}\mathrm{N}=7 \text { I ( } \mathrm{N}=5 \text { studies missing } \\
\text { for every study included in } \\
\text { the current analysis) }\end{array}$ & \\
\hline Duval and Tweedie's trim-and-fill analysis & $\begin{array}{l}\text { Funnel plot symmetrical? } \\
\mathrm{N} \text { studies missing on either side } \\
\text { of the overall mean weighted } d\end{array}$ & $\begin{array}{l}\text { Yes } \\
\text { None }\end{array}$ & \\
\hline Begg and Mazumdar rank order correlation & $\tau, P_{\text {two-tailed }}$ & $-0.09 ; P=0.66 \mathrm{I}$ & \\
\hline Egger's regression & Intercept; $P_{\text {two-tailed }}$ & $-1.21 ; P=0.276$ & \\
\hline
\end{tabular}

Note: $* p<0.05$.

Abbreviations: $\mathrm{Cl}$, confidence interval; $d$, standardized mean difference (effect size); $d f$, degrees of freedom; rTMS, repetitive transcranial magnetic stimulation; $\tau$, Kendall's correlation coefficient tau b with continuity correction.

publication bias systematically affected the results of the current analysis (Table 4).

There was a moderate antidepressant effect of rTMS because the change in mean depression scores from baseline to final was significantly higher after rTMS compared to sham in the $\mathrm{N}=14$ "new" studies ( $d=-0.42$; Table 4 and Figure 2 ). The "new" studies did not show a superior antidepressant effect of rTMS compared to the "old" studies because the overall mean weighted $d$ did not significantly differ between the two groups of studies ("old" $d=-0.54$ versus "new" $d=-0.42 ; P=0.151$; Table 4).

The $50 \%$ heterogeneity in the effect sizes among the $\mathrm{N}=14$ "new" studies (Table 4) was probably due to methodological differences among these studies in terms of depression scales used (HAMD in all $\mathrm{N}=14$ studies, MADRS in $\mathrm{N}=6$ studies, and BDI in $\mathrm{N}=3$ studies), clinical characteristics of patients (Table 3), and different parameters of rTMS (Table 2). Some of the $\mathrm{N}=14$ "new" studies did not report the above characteristics (Tables 2 and 3 ) and thus the percentage scores shown below are computed based on studies with valid responses only.

The $\mathrm{N}=40$ "old" studies and the $\mathrm{N}=14$ "new" studies were conducted on mostly middle-aged patients (aged 40 years old and above). Similarly to the "old" studies, $50 \%$ of the "new" studies utilized $60 \%$ or more female patients per study.
Like the "old" studies, most of the "new" studies were conducted on patients with (Table 3):

- treatment-resistance, defined as a failure to respond to or tolerate $\geq 2$ antidepressant trials ( $N=8 / 9,89 \%$ of studies),

- non-psychotic depression ( $\mathrm{N}=8 / 9,89 \%$ of studies), and - concurrent antidepressant treatment $(\mathrm{N}=11 / 14,79 \%$ of studies). Of these $\mathrm{N}=11$ studies, most included patients on stable doses of antidepressants ( $\mathrm{N}=10 / 11$ studies). Antidepressants were started on day 1 of the study in only $\mathrm{N}=1 / 11$ studies.

In contrast to the majority of "old" studies that had included any proportions of bipolar patients, the "new" studies were mostly conducted on patients with unipolar depression ( $\mathrm{N}=8 / 12,67 \%$ of studies).

The current results also suggest that similar properties of rTMS have been used over the last 16 years of research on depression (in studies published in 1997-2013). Similarly to the "old" studies, the most commonly utilized rTMS parameters among the "new" studies were: $10 \mathrm{~Hz}$ frequency of stimulation ( $\mathrm{N}=5 / 14,36 \%$ of studies), $110 \%$ motor threshold stimulation ( $\mathrm{N}=4 / 13,41 \%$ of studies ), 800 or 1,600 stimuli/ session ( $\mathrm{N}=4 / 10,40 \%$ of studies $), 20$ trains/session $(\mathrm{N}=6 / 13$, $46 \%$ of studies ), a $70 \mathrm{~mm}$ stimulating coil diameter $(\mathrm{N}=4 / 5$, $80 \%$ of studies), and a figure-of-eight shape of the stimulating 


\begin{tabular}{|c|c|c|c|c|c|c|c|}
\hline \multirow[t]{2}{*}{ Study } & \multirow[t]{2}{*}{ Outcome } & \multicolumn{4}{|c|}{ Statistics for each study } & \multicolumn{2}{|c|}{$\underline{\text { Sample size }}$} \\
\hline & & $\begin{array}{c}\text { Std diff } \\
\text { in means }\end{array}$ & $\begin{array}{l}\text { Lower } \\
\text { limit }\end{array}$ & $\begin{array}{l}\text { Upper } \\
\text { limit }\end{array}$ & $P$-value & Sham & rTMS \\
\hline George et $\mathrm{al}^{46} 2010$ & Combined & -0.11 & -0.40 & 0.18 & 0.456 & 94 & 88 \\
\hline Paillère Martinot et al ${ }^{50} 2010$ & Combined & -0.40 & -1.10 & 0.31 & 0.269 & 14 & 18 \\
\hline Pallanti et al ${ }^{51} 2010$ & HAMD & -1.33 & -2.01 & -0.64 & 0.000 & 20 & 20 \\
\hline Triggs et al ${ }^{52} 2010$ & Combined & -0.19 & -0.81 & 0.43 & 0.548 & 14 & 34 \\
\hline Aguirre et $a^{53} 2011$ & HAMD & -0.18 & -0.86 & 0.50 & 0.605 & 15 & 19 \\
\hline He et $a^{54} 2011$ & HAMD & -0.44 & -0.88 & 0.01 & 0.054 & 43 & 37 \\
\hline Lingeswaran et al ${ }^{55} 2011$ & Combined & -0.09 & -0.93 & 0.75 & 0.836 & 14 & 9 \\
\hline Bakim et $a^{56} 2012$ & Combined & -0.93 & -1.79 & -0.07 & 0.035 & 12 & 11 \\
\hline Blumberger et al ${ }^{57} 2012$ & HAMD & 0.22 & -0.43 & 0.87 & 0.505 & 18 & 19 \\
\hline Fitzgerald $^{58} 2012$ & Combined & -0.39 & -1.03 & 0.24 & 0.227 & 18 & 21 \\
\hline Huang et al ${ }^{59} 2012$ & Combined & -0.95 & -1.51 & -0.40 & 0.001 & 28 & 28 \\
\hline Chen et $a^{160} 2013$ & Combined & 0.38 & -0.55 & 1.30 & 0.427 & 10 & 10 \\
\hline Hernández-Ribas et al ${ }^{61}$ & HAMD & -0.89 & -1.79 & 0.01 & 0.052 & 11 & 10 \\
\hline Speer et al ${ }^{62} 2013$ & HAMD & -0.90 & -1.78 & -0.01 & 0.047 & 8 & 16 \\
\hline & & -0.42 & -0.66 & -0.18 & 0.001 & & \\
\hline
\end{tabular}
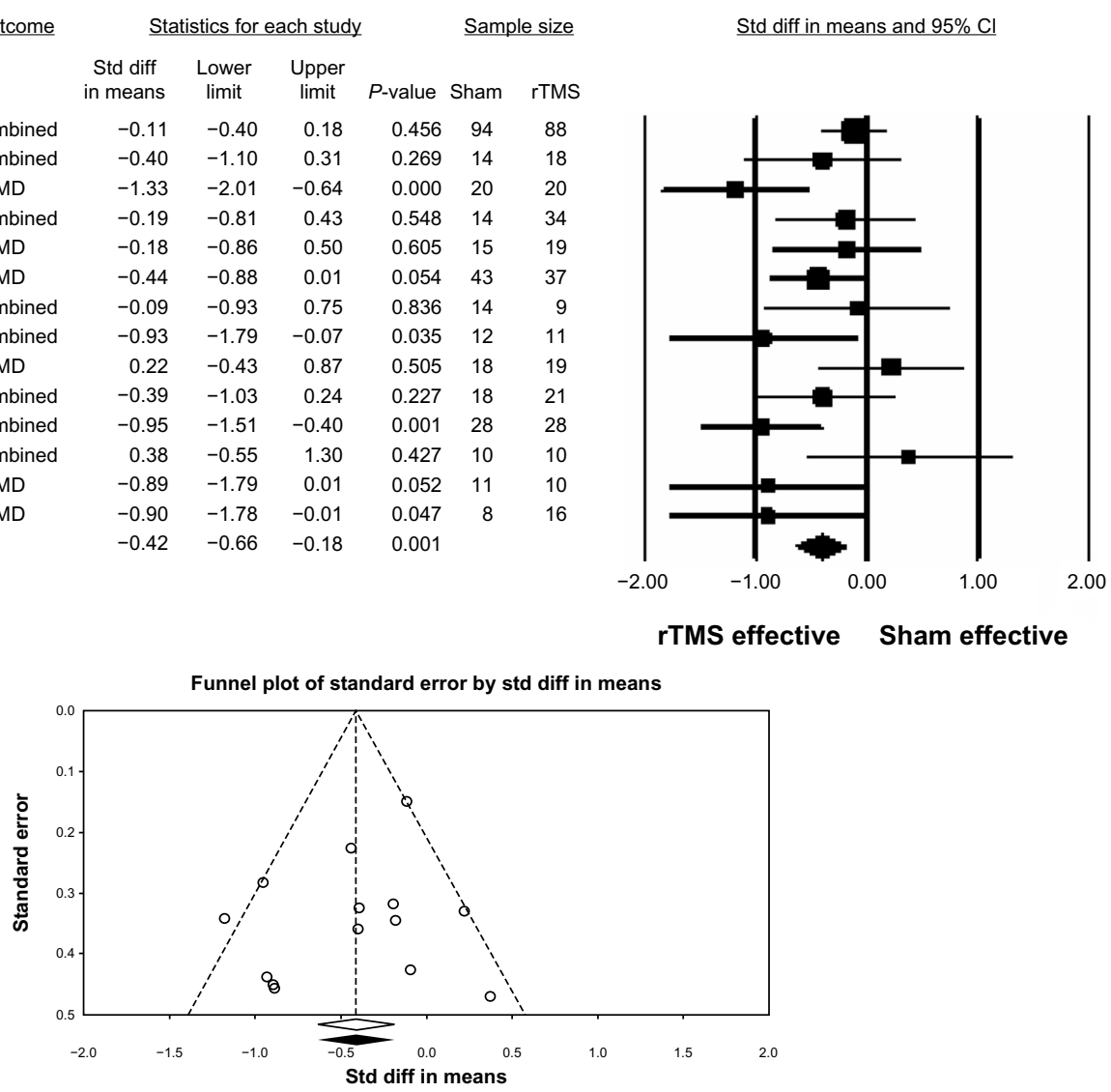

Figure 2 Random-effects meta-analysis of N=14 "new" studies (2010-2013) comparing the change in mean depression scores on HAMD, BDI, and/or MADRS (baselinefinal), after $r$ TMS versus sham.

Notes: In the studies by Triggs et al ${ }^{52}$ and Speer et al, ${ }^{62}$ rTMS was administered using different properties into different subgroups of patients in a study and the depression scores for such subgroups were combined. The mean number of patients per group was used in the final calculations if patients dropped out throughout the study between baseline and final sessions. The forest plot (top) shows the weighted effect size $d$ (box) and its $95 \% \mathrm{Cl}$ (vertical line through the box) for each study in the analysis ("combined" indicates that more than one depression scale was used in a study and the effect sizes according to the multiple scales were combined). The diamond depicts the overall mean weighted $d$ of all studies and its $95 \% \mathrm{Cl}$ (width of the diamond). The mean depression scores (baseline - final) were significantly reduced after $r$ TMS compared to sham (overall mean weighted $d=-0.41,95 \% \mathrm{Cl}:-0.64,-0.18$ ). The funnel plot (bottom) shows the effect sizes $d$ plotted versus SEM for each study in the analysis. The plot was symmetrical around the overall mean weighted $d$ suggesting that publication bias had little effect on the results of the current meta-analysis.

Abbreviations: BDI, Beck Depression Inventory; Cl, confidence interval; HAMD, Hamilton Depression Rating Scale; MADRS, Montgomery Åsberg Depression Rating Scale; rTMS, repetitive transcranial magnetic stimulation; SEM, standard error of mean; Std diff, standardized mean difference $d$.

coil ( $\mathrm{N}=13 / 13$ studies). In contrast to the 10 rTMS sessions most commonly used among the "old" studies, the "new" studies most often utilized longer paradigms of 15 sessions ( $\mathrm{N}=6 / 14,43 \%$ of studies).

Interestingly, even though the new "sham-coils" improve the blinding of studies and prevent stimulation of the brain due to an inbuilt magnetic shield, these coils have not been commonly used in the "new" studies yet (possibly due to a high cost of replacing the older stimulators with the newest ones). In fact, similarly to the "old" studies, the most common sham practice among the "new" studies was to tilt the active coil by a $90^{\circ}$ angle from the scalp ( $\mathrm{N}=6 / 14,43 \%$ of studies).

Finally, just like the "old" studies, the left-fast rTMS $(>1 \mathrm{~Hz})$ of the DLPFC was the most common combination of the location-frequency of rTMS among the "new" studies ( $\mathrm{N}=10 / 14,71 \%$ of studies), followed by the bilateral or sequential rTMS (N=3/14, $21 \%$ of studies), and the left-slow $(\leq 1 \mathrm{~Hz})$, right-slow, and right-fast rTMS that were utilized in one study $(7 \%)$ each.

Since there were too few "new" studies, we have combined all "old" and "new" studies (total $\mathrm{N}=54$ ) to conduct moderator and subgroup analyses. The results of these analyses are shown in Table 5.

The overall mean weighted $d=-0.51$ in all $\mathrm{N}=54$ studies suggests that rTMS was only moderately better than sham at reducing depression scores over the last 16 years in a total of 2,242 patients in 17 countries (Table 5; Figure S3; Table S3). Even though only moderate, this overall effect size became stable around -0.50 to -0.54 over the last 8 years as studies were removed from the analysis one at a time (Figure S4), or cumulatively added to the analysis (Figure S5).

Univariate comparisons of subgroups of studies based on common study properties showed that no one specific characteristic was superior in terms of producing higher 
Table 5 Random-effects subgroup analyses and meta-regressions of the change in depression scores (baseline - final) after rTMS compared to sham in $\mathrm{N}=54$ sham-controlled studies published in 1997 - August 2013

\begin{tabular}{|c|c|c|c|c|c|}
\hline Studies & & $\mathbf{N}$ studies $(\%)^{\mathbf{a}}$ & & $d(95 \% \mathrm{Cl})$ & $P_{\text {two-tailed }}$ \\
\hline All studies (1997-2013) & & 54 & & $-0.51(-0.63,-0.39)$ & $<0.00 I^{*}$ \\
\hline \multicolumn{6}{|l|}{ Subgroups } \\
\hline Location-frequency ${ }^{\mathrm{b}}$ & & 54 & & & \\
\hline Left-slow ( $\leq \mathrm{I} \mathrm{Hz})$ & & $4(7 \%)$ & & $-0.6 \mathrm{I}(-1.2 \mathrm{I},-0.0 \mathrm{I})$ & $0.046 *$ \\
\hline Left-fast $(>\mathrm{I} \mathrm{Hz})$ & & $43(80 \%)$ & & $-0.49(-0.63,-0.34)$ & $<0.00 I^{*}$ \\
\hline Right-slow & & $6(11 \%)$ & & $-1.01(-1.61,-0.42)$ & $0.001 *$ \\
\hline Right-fast & & I (2\%) & & $0.03(-0.86,0.92)$ & 0.948 \\
\hline Bilateral or sequential (left then right) & & $7(13 \%)$ & & $-0.55(-0.82,-0.29)$ & $<0.00 I^{*}$ \\
\hline Treatment resistance & & 27 & & & \\
\hline Yes (all failed $\geq 2 A D$ trials) & & $21(78 \%)$ & & $-0.52(-0.70,-0.35)$ & $<0.00 I^{*}$ \\
\hline No (all failed $0-I$ AD trials) & & $6(22 \%)$ & & $-0.80(-1.02,-0.50)$ & $<0.00 I^{*}$ \\
\hline Yes versus noc & & & & & 0.108 \\
\hline Concurrent medication & & 54 & & & \\
\hline YES (any \% of patients) & & $42(78 \%)$ & & $-0.5 \mathrm{I}(-0.63,-0.38)$ & $<0.001^{*}$ \\
\hline Stable dose & & $35(83 \%)$ & & $-0.5 \mathrm{I}(-0.65,-0.36)$ & $<0.00 I^{*}$ \\
\hline Started on day I & & 7 (I7\%) & & $-0.50(-0.77,-0.23)$ & $<0.00 I^{*}$ \\
\hline NO (all patients) & & $12(22 \%)$ & & $-0.56(-0.84,-0.28)$ & $<0.00 I^{*}$ \\
\hline YES versus $\mathrm{NO}^{c}$ & & & & & 0.229 \\
\hline Bipolar depression & & 42 & & & \\
\hline YES (any \% of patients) & & $23(55 \%)$ & & $-0.44(-0.60,-0.28)$ & $<0.00 I^{*}$ \\
\hline NO (all patients) & & $19(45 \%)$ & & $-0.54(-0.72,-0.34)$ & $<0.00 I^{*}$ \\
\hline YES versus $\mathrm{NO}^{c}$ & & & & & 0.921 \\
\hline Psychotic depression & & 28 & & & \\
\hline YES (any $\%$ of patients) & & $5(18 \%)$ & & $-0.51(-1.14,0.13)$ & 0.117 \\
\hline NO (all patients) & & $23(82 \%)$ & & $-0.58(-0.77,-0.40)$ & $<0.00 I^{*}$ \\
\hline YES versus $\mathrm{NO}^{c}$ & & & & & 0.745 \\
\hline Coil-type & & 51 & & & \\
\hline F8 & & 47 (92\%) & & $-0.52(-0.65,-0.38)$ & $<0.00 I^{*}$ \\
\hline Circular & & $4(8 \%)$ & & $-0.62(-1.05,-0.19)$ & $0.005^{*}$ \\
\hline F8 versus circular ${ }^{c}$ & & & & & $0.56 \mathrm{I}$ \\
\hline Coil angle sham & & 54 & & & \\
\hline $0^{\circ}$ (inactive coil) & & $5(9 \%)$ & & $-0.36(-0.64,-0.07)$ & $0.015^{*}$ \\
\hline $0^{\circ}$ (sham coil) & & $10(19 \%)$ & & $-0.63(-0.92,-0.34)$ & $<0.00 I^{*}$ \\
\hline $45^{\circ}$ & & $18(33 \%)$ & & $-0.40(-0.57,-0.22)$ & $<0.00 I^{*}$ \\
\hline $90^{\circ}$ & & 21 (39\%) & & $-0.56(-0.77,-0.35)$ & $<0.00 I^{*}$ \\
\hline $0^{\circ}$ (sham coil) versus $45^{\circ}$ & & & & & 0.757 \\
\hline \multirow[t]{2}{*}{$0^{\circ}$ (sham coil) versus $90^{\circ}$} & & & & & 0.150 \\
\hline & $\mathbf{N}$ studies & $T_{\text {total }}^{2}$ & $\mathbf{T}_{\text {model }}^{2}$ & $R^{2}$ & $P_{\text {two-tailed }}$ \\
\hline \multicolumn{6}{|l|}{ Meta-regression predictors ${ }^{d}$} \\
\hline$\%$ female patients & 53 & 0.046 & 0.022 & -0.01 & $0.002 *$ \\
\hline Stimuli/session & 33 & 0.043 & 0.004 & 0.0002 & $<0.00 I^{*}$ \\
\hline Trains/session ${ }^{e}$ & 48 & $0.07 \mid$ & 0.044 & 0.007 & $0.013^{*}$ \\
\hline
\end{tabular}

Notes: Total patients in $\mathrm{N}=54$ studies totaled $\mathrm{N}=2,242$ ( $\mathrm{rTMS} \mathrm{N}=\mathrm{I}, 184$, sham $\mathrm{N}=1,058$ ). ${ }^{\mathrm{a}}$ The percent values are reported based on the number of studies that reported a particular characteristic; beffect sizes in subgroups based on location-frequency of rTMS were not compared statistically because some studies used multiple active rTMS groups but the same sham groups, and thus the subgroups were not independent; 'subgroups were compared using the mixed-effect model; random-effects model was used to compute the overall mean weighted $d$ in each subgroup and overall mean weighted $d$ of subgroups were compared using the fixed-effect model because the number of subgroups was fixed; dproportion of the between-study variance in weighted $d$ explained by the predictor was computed as $R^{2}=I-\left(T^{2}{ }_{\text {model }} / T^{2}\right.$ total $)$, where $T^{2}{ }_{\text {model }}$ is the betweenstudy variance in the weighted $d$ (outcome) unexplained by the regression model containing the predictor and $T^{2}$ is the within- and between-study variance; ${ }^{29}$ efollowing the Bonferroni correction for multiple regressions (new significance threshold of $0.05 / 7=0.007$ ), the regression of trains/session on weighted $d$ became non-significant. $* P<0.05$. Abbreviations: $\mathrm{AD}$, antidepressant; $\mathrm{Cl}$, confidence interval; rTMS, repetitive transcranial magnetic stimulation.

antidepressant effects. For example, except for the rightfast rTMS of the DLPFC that was utilized in only one study, all combinations of the location-frequency of rTMS were effective at significantly reducing depression scores compared to sham (Table 5). There was a non-significant trend toward higher overall mean weighted effect sizes in studies with non-treatment resistant patients compared to those with treatment-resistant patients (Table 5). rTMS was also similarly effective in studies with unipolar depression compared to studies with generally low proportions of 
bipolar patients (Table 5). However, it remains unclear if the antidepressant properties of rTMS extend to psychotic depression because there were too few studies with low proportions of patients with psychotic depression in the current analysis $(\mathrm{N}=5$; Table 5).

According to the current results, the antidepressant effect of rTMS was probably not secondary to concurrent antidepressants. Table 5 shows that depression was reduced after rTMS compared to sham in studies with patients who were medication-free or started on antidepressants concurrently with rTMS on day 1 of a study. Overall mean weighted effect sizes did not differ statistically between studies with medicated versus medication-free patients (Table 5).

The current study also shows that depression was reduced after rTMS compared to sham using both stimulating coil shapes (figure-of-eight or circular) and various sham designs. Although studies using sham coils produced the highest overall mean weighted effect size ( $d=-0.63$; Table 5 ) compared to all other sham designs, more than $\mathrm{N}=10$ studies using sham coils are needed to statistically confirm the superiority of this blinding method. Compared to sham coils, tilting of active coils at $45^{\circ}$ or $90^{\circ}$ from the scalp was the most commonly used sham practice in studies published until August 2013 (Table 5). The most commonly used stimulators were the MagStim (UK; N=28/54, 52\% of studies) and the MagPro (USA; $\mathrm{N}=10 / 54,18 \%$ of studies) models.

Finally, seven univariate meta-regressions were conducted to find out if any demographic characteristics of patients (mean age/study and proportion of female patients/study) or rTMS parameters (frequency of stimulation, motor threshold, total number of sessions, stimuli/session, trains/session) could predict a change in the effect sizes weighted according to the random-effects model. Two regressions showed that the antidepressant effect of rTMS was superior in studies with more female patients and fewer stimuli per session (Table 5; Figure 3 ). However, a change in weighted $d$ s could not be significantly predicted using the mean age of all patients per study, frequency of stimulation, motor threshold, or a total number of sessions as predictors. Predictors "stimuli/session" and " $\%$ female patients" explained $91 \%$ and $52 \%$ of the between-study variability in effect sizes, respectively.

\section{Discussion}

The current meta-analysis conducted on $\mathrm{N}=54$ studies published in 1997-2013 showed that rTMS has a short-term antidepressant effect that is superior in studies with more female patients and fewer stimuli per session (Table 5 and
Figure 3). The most commonly used characteristics of patients and rTMS parameters in the sham-controlled studies over the last 16 years (1997-2013) included in the current analysis were: at least $60 \%$ female patients/study in half of all studies (range: 22\%-92\%); mostly middle-aged or older patients (range of the mean age of all patients per study: 39-62 years); fast ( $>1 \mathrm{~Hz})$ stimulation of the left DLPFC; frequency of $10 \mathrm{~Hz} ; 110 \%$ motor threshold; figure-of-eight coil with $70 \mathrm{~mm}$ diameter; 1,600 stimuli/session; 20 trains/ session; and 10 sessions/study (although the more recent studies published after 2008 most commonly used longer protocols of 15 sessions/study). The most commonly used sham strategy was tilting of the active coil at the $90^{\circ}$ angle from scalp (Table 5). Most of the studies to date included proportions of patients with treatment resistance, on concurrent antidepressants (particularly at the stable dose), with bipolar and non-psychotic depression (Table 5).

It is likely that sex plays a role in the short-term response to the left-fast rTMS because $80 \%$ of all studies in the current meta-analysis utilized this combination of rTMS parameters (Table 5). This result confirms another univariate finding that out of patients who failed to respond to a 4-week, double-blind phase of rTMS in a large RCT, ${ }^{42}$ only females showed a superior response to rTMS during the extension (open-label) phase of the study. ${ }^{5}$ However, such a response to treatment was probably related to a combination of factors rather than sex alone. This is because the patients in the RCT were unipolar, non-psychotic, medication-free, moderately-severely treatment-resistant, and required more than four weeks of treatment to respond to rTMS. ${ }^{5}$ Another open-label study also showed that the improved response to rTMS in females depended on younger (premenopausal) age and the ovarian hormonal levels. ${ }^{43}$ Such a result is not surprising because depression has a strong hormonal component. ${ }^{44,45}$ Thus, it can be speculated that the superior effect of sex in our meta-analysis was also due to younger age of female patients, and other factors (such as less severe unipolar depression and/or medication-free status). However, such confounding factors can be investigated only to a limited extent in metaanalyses that are computed on data. It should be possible to compute multiple meta-regressions on group data as new studies using rTMS become available in the future, providing that these studies report the characteristics of their patients and/or rTMS properties used.

The second important finding in the current meta-analysis is that the short-term antidepressant properties of rTMS were observed in studies using fewer stimuli per session according to a univariate meta-regression (Table 5 and Figure 3). 
Other meta-analyses showed that the efficacy of rTMS was not associated with the number of stimuli/session nor total stimuli. ${ }^{14,19,20,23}$ The initial negative correlation between the effect sizes and the total number of stimuli in one metaanalysis ${ }^{20}$ was attributed to one large RCT only. ${ }^{42}$ Similarly, this and another large $\mathrm{RCT}^{42,46}$ contributed to the additional significant univariate meta-regression of the total number of stimuli (computed as "stimuli per session" $\times$ "total sessions" per study based on the data shown in Table 2) on weighted $d$ in the current analysis (Figure S6). However, the meta-regression of stimuli/session on weighted $d$ remained unchanged after the removal of the same two RCTs ${ }^{42,46}$ in the current analysis (Figure S7). In general, the findings from the two largest RCTs ${ }^{42,46}$ suggest that the initially non-responsive patients appear to indeed require more than 15 rTMS sessions with a high number $(3,000)$ of stimuli/session to show a response to rTMS. However, the results of the current meta-analysis suggest that the short-term response to rTMS (during the double-blind phase of the study) might require fewer stimuli per session. Again, based on the current results, it can only be speculated that particularly the less treatmentresistant female patients require fewer stimuli per session in the short (up to 10 sessions), left-fast rTMS paradigms to demonstrate the antidepressant response to rTMS.

Interestingly, some evidence in support of the speculation above can be found in three of the four studies classified as outliers in the current analysis. Specifically, a large antidepressant effect of rTMS was observed in the total of $\mathrm{N}=86$ patients $(63 \%-65 \%$ males $)$ on concurrent antidepressants, with unipolar, non-psychotic depression, and with moderate-severe treatment-resistance using long (20 sessions), left-fast paradigms with a high number $(3,000)$ of stimuli/session. ${ }^{38,40,41}$ Therefore, in contrast to female patients, male patients with more severe major depression might require longer, left-fast paradigms with more stimuli per session to show an antidepressant response to rTMS during the double-blind phases of studies. Furthermore, such a sexdependent effect could also explain why the two largest RCTs to date, with similar study characteristics to those in the three outlier studies, have demonstrated only small antidepressant effects of rTMS in mostly female (medication-free) patients: $d=-0.30$ in $\mathrm{N}=301$ patients $^{42}$ (Figure $\mathrm{S} 1$ ) and $d=-0.11$ in $\mathrm{N}=190$ patients $^{46}$ (Figure 2). Such small effect sizes might have resulted from a high quality of blinding (with sham coils) in the RCTs compared to the large effect sizes using tilted active coils in the outlier studies. Thus, future primary studies should investigate the effects of rTMS separately in both sexes controlling for severity of treatment resistance and the number of stimuli/session in the left-fast rTMS paradigms.

The significant reduction in depression scores after rTMS associated with fewer stimuli per session raises the question of whether or not the brain can be "overstimulated" during rTMS leading to a reduction in the antidepressant properties of this method. One mechanism of such an "overstimulation" could be related to the firing properties of neurons. In general, voltage-gated sodium channels are key players in membrane excitation and the production of action potentials. The classical model of sodium channel gating described by Hodgkin and Huxley suggests that a voltage-gated mechanism mediates the activation (opening of sodium channels) as well as inactivation following a refractory period during which no excitation can occur. ${ }^{47} \mathrm{~A}$ strong depolarization involving a large number of neurons can inactivate sodium channels and thereby prevent further excitation for a prolonged period of time. Since neurons need to recover from firing before being able to produce new action potentials, stimulating the brain with too many stimuli might lead to a neural saturation (inability of most neurons to produce new action potentials) and consequently a reduction in antidepressant properties of rTMS. In practical terms, using shorter sessions with fewer stimuli could be less costly as well as time consuming for patients and administrators.

Univariately, the mean age of all patients (rather than age of individual patients) was not related to a better antidepressant outcome of rTMS in the current and past metaanalyses ${ }^{14,20}$ possibly due to the use of group data. Similarly, effect sizes were unrelated to severity of treatment-resistance or presence versus absence of treatment-resistant patients in other meta-analyses. ${ }^{14,16,17,20}$ In our analysis there was only a trend toward higher antidepressant effect of rTMS in (very few) studies with non-treatment-resistant patients compared to studies with treatment-resistant patients (Table 5). The reason for this result could be that we have not controlled for severity of illness in our meta-analysis. Furthermore, our classification of studies into subgroups was also not optimal for unipolar versus bipolar and psychotic versus non-psychotic depression. In general, very few patients had such diagnoses per study (Table 3). Thus, there was no difference in effect sizes between groups of studies with all unipolar and all non-psychotic patients compared to studies with mostly unipolar and mostly non-psychotic patients, respectively (Table 5). Other meta-analyses have also found no differences in effect sizes or response and remission rates between studies with unipolar compared to bipolar patients. ${ }^{14,23}$ While effect sizes were higher in studies 


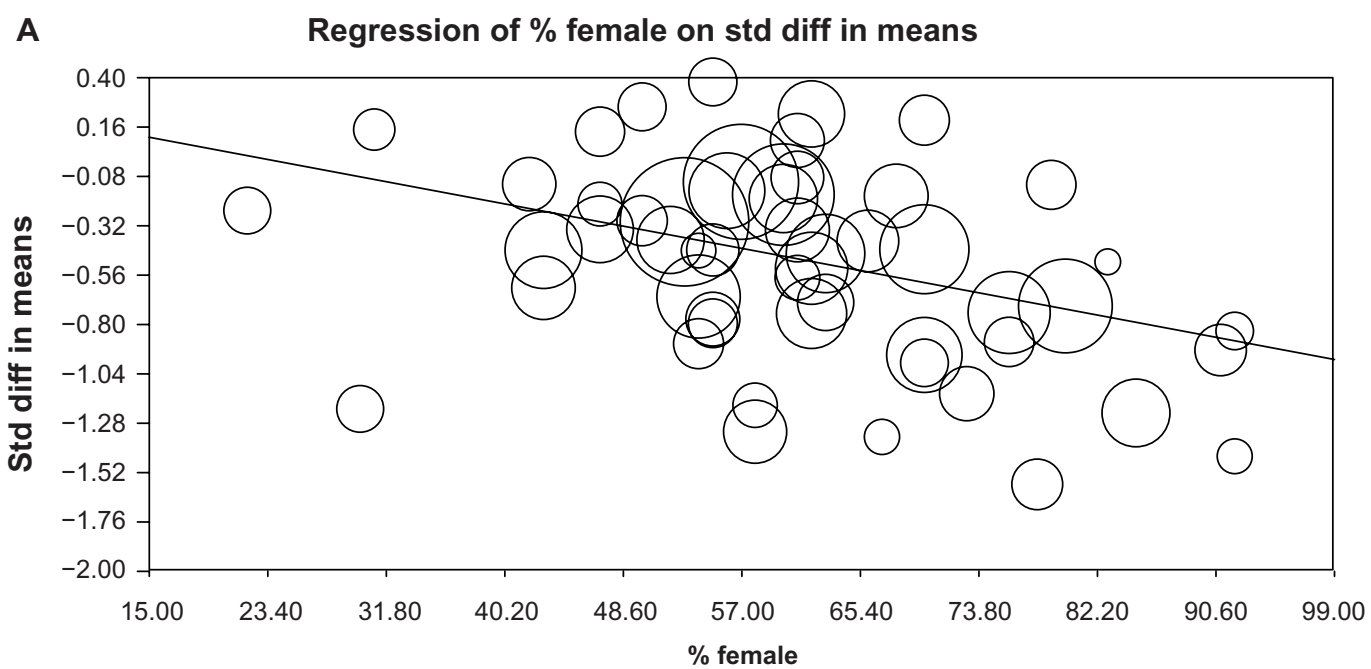

B Regression of stimuli on std diff in means

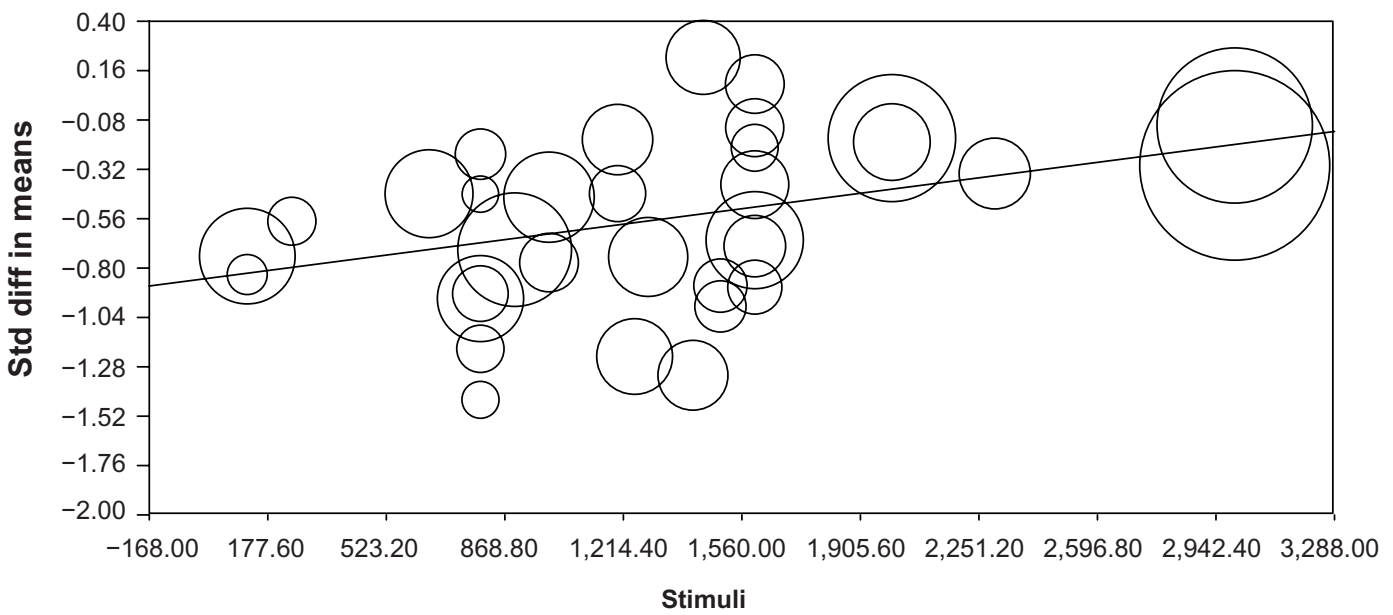

Figure 3 Univariate random-effects meta-regressions of various study characteristics used as predictors (proportion of female patients/study and stimuli/session) on the weighted effect sizes $d$ (the outcome) in studies published in 1997-2013.

Notes: The figures are scatterplots of the outcome (weighted d/study; Y-axes) versus predictors (X-axes): (A) proportion of female patients/study and (B) stimuli/session. Depression scores (baseline - final) were significantly reduced after rTMS compared to sham in studies with more female patients and less stimuli/session.

Abbreviations: rTMS, repetitive transcranial magnetic stimulation; Std diff, standardized mean difference $d$.

with non-psychotic versus psychotic patients in one metaanalysis, ${ }^{19}$ such result was not confirmed by another metaanalysis, ${ }^{14}$ possibly due to including studies with unknown psychosis status in the non-psychotic group.

The short-term antidepressant effect of rTMS was not secondary to concurrent antidepressants in the current analysis. Specifically, it was observed in studies with patients who were all medication-free or who started on antidepressants concurrently with rTMS (Table 5). However, the current analysis did not confirm the finding from other meta-analyses that the short-term response to rTMS was higher ${ }^{23}$ or tended to be higher ${ }^{19}$ in studies using rTMS as monotherapy versus an add-on therapy. The reason for this result might be that we have not controlled for proportions of patients on concurrent antidepressants in the add-on studies.

According to our results depression severity was reduced after rTMS compared to sham in studies using different rTMS properties, such as different stimulating coils (figureof-eight or circular), different sham paradigms, and different combinations of the location (right or left) and frequency (slow or fast) of DLPFC stimulation (Table 5). Although blinding is facilitated by the use of shielded sham coils that resemble active coils visually and produce similar auditory effects while not stimulating the brain ${ }^{48}$ these coils were still not commonly used compared to tilting of active coils (possibly due to high costs of replacing the older with newer 
equipment). Furthermore, except for five studies, all other studies used the "5 cm rule" to define the position of the DLPFC (Table 2) in the current analysis. Even though it is so frequently used, the " $5 \mathrm{~cm}$ rule" is less accurate than the 10-20 EEG (electroencephalogram) system and the magnetic resonance image (MRI)-guided neuronavigation. ${ }^{49}$ Therefore, the antidepressant properties of rTMS could be further strengthened by the use of either MRI or the F5 location of the EEG system. ${ }^{49}$

The moderate effect sizes in the current and most other meta-analyses on this topic could be related to statistical methods of computing the effect sizes and performing a meta-analysis. The magnitude of effect sizes in individual studies might largely depend on the blinding quality of studies and the computation of effect sizes. Therefore, assuming that baseline depression scores are similar, the well-blinded studies could have smaller standardized differences in mean depression scores between rTMS and sham groups. This is because patients could respond to rTMS (due to its antidepressant properties) and to sham (due to placebo effect) in well-blinded studies. In contrast, the poorly-controlled studies in which patients and/or administrators guess the treatment allocation could show larger effect sizes. This time patients could respond to rTMS (guessing that they receive the real treatment) but not to sham (guessing that they receive the inactive treatment). This scenario is possible because patients can easily inform themselves about the method from the social media, for instance by watching industry-sponsored videos on YouTube directed toward the general population.

Furthermore, the past meta-analyses in this field used two general approaches to computing the effect sizes: the mean depression scores were compared before versus after rTMS or sham (in some studies controlling for baseline depression scores) using standardized mean differences (Cohen's $d$ or Hedges' $g$ ), or proportions of patients who remitted after rTMS or sham versus baseline were compared using the odds ratios. None of these approaches of computing effect sizes is ideal from the statistical point of view. Mean scores could be skewed in studies with small sample sizes ( $<30$ patients). Thus, the "true average" depression score would be shown more accurately using the mode (most commonly occurring depression score in the rTMS versus sham groups) or the median rather than the skewed mean. On the other hand, the odds ratios are also problematic because they rely on classifying patients into two groups (non-depressed versus depressed) based on a subjective cut-off on a depression scale. As a result, a patient with a score of 17 on a specific scale might be classified as "non-depressed" while another one with a score of 18 might already fall into the "depressed group" regardless of such a low difference between their scores. Furthermore, the odds ratios computed from each primary study would need to be based on the same cut-off for presence/absence of depression to reliably combine the results of these studies in meta-analysis. Therefore, the "all or nothing" classification of patients according to the odds ratio might be reliable and valid when large differences among patients' scores occur and thus the group membership can be reliably justified. Despite the limitations above, the advantage of mean scores is that they show the severity of depression without needing a specific cut-off to classify patients into groups.

Furthermore, different methods of weighing of studies and meta-analysis were utilized in the meta-analyses to date. The weights in the current meta-analysis were computed based on variance. Therefore, studies with higher variability of scores (due to rTMS being effective at reducing depression in only some, but not all, patients) had lower weights and thus lower influence on the overall mean weighted effect size. However, other methods of meta-analysis advocate the use of other weighing methods, such as the sample size, and correcting the effect sizes in individual studies for study-related artifacts before conducing any meta-analysis. ${ }^{29}$ Despite all the statistical differences, most of the past 17 meta-analyses (published 2001-2013) and the current meta-analysis report similar (moderate) weighted effect sizes (standardized mean differences or odds ratios). Therefore, it is likely that the true effect of rTMS is either only moderate or indeed even higher in clinical practice considering the statistical limitations described above.

Although no strong evidence for publication bias was detected in the current study (Table 4), the sources included in our analysis were biased toward studies published in peerreviewed journals and written in the English language. Such an apparent bias in selection of sources was not related to the systematic search strategy (Table 1). Our search was conducted for any type of resource (published or not published) in any language (because the authors of this study are multilingual speakers of six different languages). Instead, it appears that the majority of sources on this topic on PsycInfo and Medline were indeed published in peer-reviewed journals and written in English (or at least included a title and an abstract written in English). Therefore, such a linguistic bias is probably related to the fact that PsycInfo and Medline mostly store published sources and these sources are most often written in English. However, the results of our 
analysis are generalizable beyond the English-speaking world because the $\mathrm{N}=54$ studies were conducted in a total of 17 countries around the world (for the list see Table S3). According to the File Drawer Problem ${ }^{33}$ studies with statistically significant results are more likely to be published while those with non-significant results remain in "file drawers" and are never published. Even though such so-called "gray (unpublished) literature" was not included, only 50\% of all studies in the current meta-analysis reached the traditional significance level (Figure S3). Furthermore, no checklist for the quality of studies was used in the current analysis. Instead, the quality of studies was assessed indirectly by weighing the effect sizes based on variability of scores within and between studies. It was assumed that studies with low variability of scores were of higher quality and thus contributed more weight to the overall mean weighted effect sizes and vice-versa.

\section{Conclusion}

In conclusion, the results of the current study suggest that the short-term antidepressant properties of rTMS are not secondary to concurrent antidepressants and might depend on sex and the number of stimuli per session. Depending on degree of treatment-resistance and age, male and female patients with unipolar depression might require paradigms with different properties (number of stimuli per session, total number of sessions, left-fast or other combinations of location-frequency of stimulation) to show comparable antidepressant effects. While the clinical efficacy of the fast rTMS of the left DLPFC seems to be widely accepted, the right-slow and bilateral or sequential paradigms appear to be promising alternatives in the short-term treatment of acute major depression.

\section{Author contributions}

VA conducted the systematic search and assessed all studies for inclusion with KKK. The data were independently extracted by KKK and SKR (studies up to 2008), and KKK and VA (2009-2013). VA performed the pilot analyses in SPSS/CMA, while KKK performed the final analyses in SPSS/CMA and wrote the manuscript. All authors critically revised the manuscript.

\section{Acknowledgments}

We would like to thank the authors of four studies for additional data and Ms Anja Kakau (Systems Librarian at Jacobs University) for her assistance with the literature search.

\section{Disclosure}

The authors report no conflicts of interest in this work. No external funding was received for this study.

\section{References}

1. Fregni F, Marcolin MA, Myczkowski M, et al. Predictors of antidepressant response in clinical trials of transcranial magnetic stimulation. Int J Neuropsychopharmacol. 2006;9(6):641-654.

2. Kozel FA, Nahas Z, deBrux C, et al. How coil-cortex distance relates to age, motor threshold, and antidepressant response to repetitive transcranial magnetic stimulation. J Neuropsychiatry Clin Neurosci. 2000;12(3):376-384.

3. Brakemeier EL, Luborzewski A, Danker-Hopfe H, Kathmann N, Bajbouj M. Positive predictors for antidepressive response to prefrontal repetitive transcranial magnetic stimulation (rTMS). J Psychiatr Res. 2007;41(5):395-403.

4. Brakemeier EL, Wilbertz G, Rodax S, et al. Patterns of response to repetitive transcranial magnetic stimulation (rTMS) in major depression: replication study in drug-free patients. J Affect Disord. 2008;108(1-2):59-70.

5. Lisanby SH, Husain MM, Rosenquist PB, et al. Daily left prefrontal repetitive transcranial magnetic stimulation in the acute treatment of major depression: clinical predictors of outcome in a multisite, randomized controlled clinical trial. Neuropsychopharmacology. 2009;34(2):522-534.

6. McDonald WM, Durkalski V, Ball ER, et al. Improving the antidepressant efficacy of transcranial magnetic stimulation: maximizing the number of stimulations and treatment location in treatment-resistant depression. Depression Anxiety. 2011;28(11):973-980.

7. McNamara B, Ray JL, Arthurs OJ, Boniface S. Transcranial magnetic stimulation for depression and other psychiatric disorders. Psychol Med. 2001;31(7):1141-1146.

8. Holtzheimer PE, Russo J, Avery DH. A meta-analysis of repetitive transcranial magnetic stimulation in the treatment of depression. Psychopharmacol Bull. 2001;35(4):149-169.

9. Martin JL, Barbanoj MJ, Schlaepfer TE, et al. Transcranial magnetic stimulation for treating depression. Cochrane Database Syst Rev. 2002;(2):CD003493.

10. Kozel FA, George MS. Meta-analysis of left prefrontal repetitive transcranial magnetic stimulation (rTMS) to treat depression. $J$ Psychiatr Pract. 2002;8(5):270-275.

11. Burt T, Lisanby SH, Sackeim HA. Neuropsychiatric applications of transcranial magnetic stimulation: a meta analysis. Int $J$ Neuropsychopharmacol. 2002;5(1):73-103.

12. Martin JL, Barbanoj MJ, Schlaepfer TE, Thompson E, Pérez V, Kulisevsky J. Repetitive transcranial magnetic stimulation for the treatment of depression. Systematic review and meta-analysis. $\mathrm{Br} J$ Psychiatry. 2003;182:480-491.

13. Couturier JL. Efficacy of rapid-rate repetitive transcranial magnetic stimulation in the treatment of depression: a systematic review and meta-analysis. J Psychiatry Neurosci. 2005;30(2):83-90.

14. Herrmann LL, Ebmeier KP. Factors modifying the efficacy of transcranial magnetic stimulation in the treatment of depression: a review. J Clin Psychiatry. 2006;67(12):1870-1876.

15. Gross M, Nakamura L, Pascual-Leone A, Fregni F. Has repetitive transcranial magnetic stimulation (rTMS) treatment for depression improved? A systematic review and meta-analysis comparing the recent vs the earlier rTMS studies. Acta Psychiatr Scand. 2007;116(3):165-173.

16. Lam RW, Chan P, Wilkins-Ho M, Yatham LN. Repetitive transcranial magnetic stimulation for treatment-resistant depression: a systematic review and metaanalysis. Can J Psychiatry. 2008;53(9): 621-631.

17. Schutter DJ. Antidepressant efficacy of high-frequency transcranial magnetic stimulation over the left dorsolateral prefrontal cortex in double-blind sham-controlled designs: a meta-analysis. Psychol Med. 2009;39(1):65-75. 
18. Schutter DJ. Quantitative review of the efficacy of slow-frequency magnetic brain stimulation in major depressive disorder. Psychol Med. 2010;40(11):1789-1795.

19. Slotema CW, Blom JD, Hoek HW, Sommer IE. Should we expand the toolbox of psychiatric treatment methods to include Repetitive Transcranial Magnetic Stimulation (rTMS)? A meta-analysis of the efficacy of rTMS in psychiatric disorders. J Clin Psychiatry. 2010;71(7):873-884.

20. Allan CL, Herrmann LL, Ebmeier KP. Transcranial magnetic stimulation in the management of mood disorders. Neuropsychobiology. 2011;64(3):163-169.

21. Berlim MT, Van den Eynde F, Daskalakis ZJ. A systematic review and meta-analysis on the efficacy and acceptability of bilateral repetitive transcranial magnetic stimulation (rTMS) for treating major depression. Psychol Med. 2013;43(11):2245-2254.

22. Berlim MT, Van den Eynde F, Daskalakis ZJ. High-frequency repetitive transcranial magnetic stimulation accelerates and enhances the clinical response to antidepressants in major depression: a meta-analysis of randomized, double-blind, and sham-controlled trials. J Clin Psychiatry. 2013;74(2):e122-e129.

23. Berlim MT, Van den Eynde F, Jeff Daskalakis Z. Clinically meaningful efficacy and acceptability of low-frequency repetitive transcranial magnetic stimulation (rTMS) for treating primary major depression: a meta-analysis of randomized, double-blind and sham-controlled trials. Neuropsychopharmacology. 2013;38(4):543-551.

24. Dell'Osso B, Camuri G, Castellano F, et al. Meta-Review of Metanalytic Studies with Repetitive Transcranial Magnetic Stimulation (rTMS) for the Treatment of Major Depression. Clin Pract Epidemiol Ment Health. 2011;7:167-177.

25. Moher D, Liberati A, Tetzlaff J, Altman DG; PRISMA group. Preferred reporting items for systematic reviews and meta-analyses: the PRISMA statement. Ann Intern Med. 2009;151(4):264-269.

26. Hamilton M. A rating scale for depression. J Neurol Neurosurg Psychiatry. 1960;23:56-62.

27. Beck AT, Ward CH, Mendelson M, Mock J, Erbaugh J. An inventory for measuring depression. Arch Gen Psychiatry. 1961;4:561-571.

28. Montgomery SA, Asberg M. A new depression rating scale designed to be sensitive to change. Br J Psychiatry. 1979;134:382-389.

29. Borenstein M, Hedges LV, Higgins JPT, Rothstein HR. Introduction to Meta-Analysis. Hoboken, NJ: John Wiley and Sons, Ltd; 2009.

30. Cohen J. Statistical Power Analysis for the Behavioural Sciences. Hillsdale, NJ: Lawrence Erlbaum Associates; 1988.

31. DerSimonian R, Laird N. Meta-analysis in clinical trials. Control Clin Trials. 1986;7(3):177-188.

32. Higgins JP, Thompson SG, Deeks JJ, Altman DG. Measuring inconsistency in a meta-analyses. BMJ. 2003;327(7414):557-560.

33. Rosenthal R. The 'file drawer' problem and tolerance for null results. Psychological Bulletin. 1979;86(3):638-641.

34. Duval S, Tweedie R. A nonparametric 'trim and fill' method of accounting for publication bias in meta-analysis. J Am Stat Assoc. 2000;95(449):89-98.

35. Sterne JA, Egger M. Funnel plots for detecting bias in meta-analysis: guidelines on choice of axis. J Clin Epidemiol. 2001;54(10):1046-1055.

36. Begg CB, Mazumdar M. Operating characterstics of a rank correlation test for publication bias. Biometrics. 1994;50(4):1088-1101.

37. Egger M, Smith GD, Schneider M, Minder C. Bias in meta-analysis detected by a simple graphical test. BMJ. 1997;315(7109):629-634.

38. Peng H, Zheng H, Li L, et al. High-frequency rTMS treatment increases white matter FA in the left middle frontal gyrus in young patients with treatment-resistant depression. J Affect Disord. 2012;136(3):249-257.

39. Ray S, Nizamie SH, Akhtar S, Praharaj SK, Mishra BR, Zia-ul-Haq M. Efficacy of adjunctive high frequency repetitive transcranial magnetic stimulation of left prefrontal cortex in depression: A randomized sham controlled study. J Affect Disord. 2011;128(1-2):153-159.

40. Spampinato C, Aguglia E, Concerto C, et al. Transcranial magnetic stimulation in the assessment of motor cortex excitability and treatment of drug-resistant major depression. IEEE Trans Neural Syst Rehabil Eng. 2013;21(3):391-403.
41. Zheng H, Zhang L, Li L, et al. High-frequency rTMS treatment increases left prefrontal myo-inositol in young patients with treatmentresistant depression. Prog Neuropsychopharmacol Biol Psychiatry. 2010;34(7):1189-1195.

42. O'Reardon JP, Solvason HB, Janicak PG, et al. Efficacy and safety of transcranial magnetic stimulation in the acute treatment of major depression: a multisite randomized controlled trial. Biol Psychiatry. 2010;67(2):e15-e17.

43. Huang CC, Wei IH, Chou YH, Su TP. Effect of age, gender, menopausal status, and ovarian hormonal level on rTMS in treatment-resistant depression. Psychoneuroendocrinology. 2008;33(6):821-831.

44. Fernández-Guasti A, Fiedler JL, Herrera L, Handa RJ. Sex, stress, and mood disorders: at the intersection of adrenal and gonadal hormones. Horm Metab Res. 2012;44(8):607-618.

45. Quera Salva MA, Hartley S. Mood disorders, circadian rhythms, melatonin and melatonin agonists. J Cent Nerv Syst Dis. 2012;4:15-26.

46. George MS, Lisanby SH, Avery D, et al. Daily left prefrontal transcranial magnetic stimulation therapy for major depressive disorder: a sham-controlled randomized trial. Arch Gen Psychiatry. 2010;67(5): 507-516.

47. Kandel ER, Schwartz JH, Jessell TM, Siegelbaum SA, Hudspeth AJ, editors. Principles of Neural Science. 5th ed. New York: McGraw-Hill Professional; 2013.

48. Berlim MT, Broadbent HJ, Van den Eynde F. Blinding integrity in randomized sham-controlled trials of repetitive transcranial magnetic stimulation for major depression: a systematic review and meta-analysis. J Neuropsychopharmacol. 2013;16(5):1173-1181.

49. Rusjan PM, Barr MS, Farzan F, et al. Optimal transcranial magnetic stimulation coil placement for targeting the dorsolateral prefrontal cortex using novel magnetic resonance image-guided neuronavigation. Hum Brain Mapp. 2010;31(11):1643-1652.

50. Paillère Martinot ML, Galinowski A, Ringuenet D, et al. Influence of prefrontal target region on the efficacy of repetitive transcranial magnetic stimulation in patients with medication-resistant depression: a [(18)F]-fluorodeoxyglucose PET and MRI study. Int J Neuropsychopharmacol. 2010;13(1):45-59.

51. Pallanti S, Bernardi S, Di Rollo A, Antonini S, Quercioli L. Unilateral low frequency versus sequential bilateral repetitive transcranial magnetic stimulation: is simpler better for treatment of resistant depression? Neuroscience. 2010;167(2):323-328.

52. Triggs WJ, Ricciuti N, Ward HE, et al. Right and left dorsolateral pre-frontal rTMS treatment of refractory depression: A randomized, sham-controlled trial. Psychiatry Res. 2010;178(3):467-474.

53. Aguirre I, Carretero B, Ibarra O, et al. Age predicts low-frequency transcranial magnetic stimulation efficacy in major depression. J Affect Disord. 2011;130(3):466-469.

54. He ML, Gu ZT, Wang XY, Shi HP. Treatment of depression using sleep electroencephalogram modulated repetitive transcranial magnetic stimulation. Chin Med J (Engl). 2011;124(12):1779-1783.

55. Lingeswaran A. Repetitive Transcranial Magnetic Stimulation in the Treatment of depression: A Randomized, Double-blind, Placebocontrolled Trial. Indian J Psychol Med. 2011;33(1):35-44.

56. Bakim B, Uzun UE, Karamustafalioglu O, et al. The combination of antidepressant drug therapy and high-frequency repetitive transcranial magnetic stimulation in medication-resistant depression. $B C P$. 2012;22(3):244-253.

57. Blumberger DM, Mulsant BH, Fitzgerald PB, et al. A randomized double-blind sham-controlled comparison of unilateral and bilateral repetitive transcranial magnetic stimulation for treatment-resistant major depression. World J Biol Psychiatry. 2012;13(6):423-435.

58. Fitzgerald PB, Hoy KE, Herring SE, et al. A double blind randomized trial of unilateral left and bilateral prefrontal cortex transcranial magnetic stimulation in treatment resistant major depression. J Affect Disord. 2012;139(2):193-198.

59. Huang ML, Luo BY, Hu JB, et al. Repetitive transcranial magnetic stimulation in combination with citalopram in young patients with first-episode major depressive disorder: a double-blind, randomized, sham-controlled trial. Aust N Z J Psychiatry. 2012;46(3):257-264. 
60. Chen SJ, Chang CH, Tsai HC, Chen ST, Lin CCh. Superior antidepressant effect occurring 1 month after rTMS: add-on rTMS for subjects with medication-resistant depression. Neuropsychiatr Dis Treat. 2013;9:397-401.

61. Hernández-Ribas R, Deus J, Pujol J, et al. Identifying brain imaging correlates of clinical response to repetitive transcranial magnetic stimulation (rTMS) in major depression. Brain Stimul. 2013;6(1):54-61.
62. Speer AM, Wassermann EM, Benson BE, Herscovitch P, Post RM. Antidepressant efficacy of high and low frequency rTMS at $110 \%$ of motor threshold versus sham stimulation over left prefrontal cortex. Brain Stimul. 2013;7(1):36-41. 


\section{Supplementary materials}

Table SI A list of $\mathrm{N}=\mathbf{4 0}$ "old" studies on the association between rTMS from our previous meta-analysis (unpublished). These studies were included in sensitivity and moderator analyses in the current study

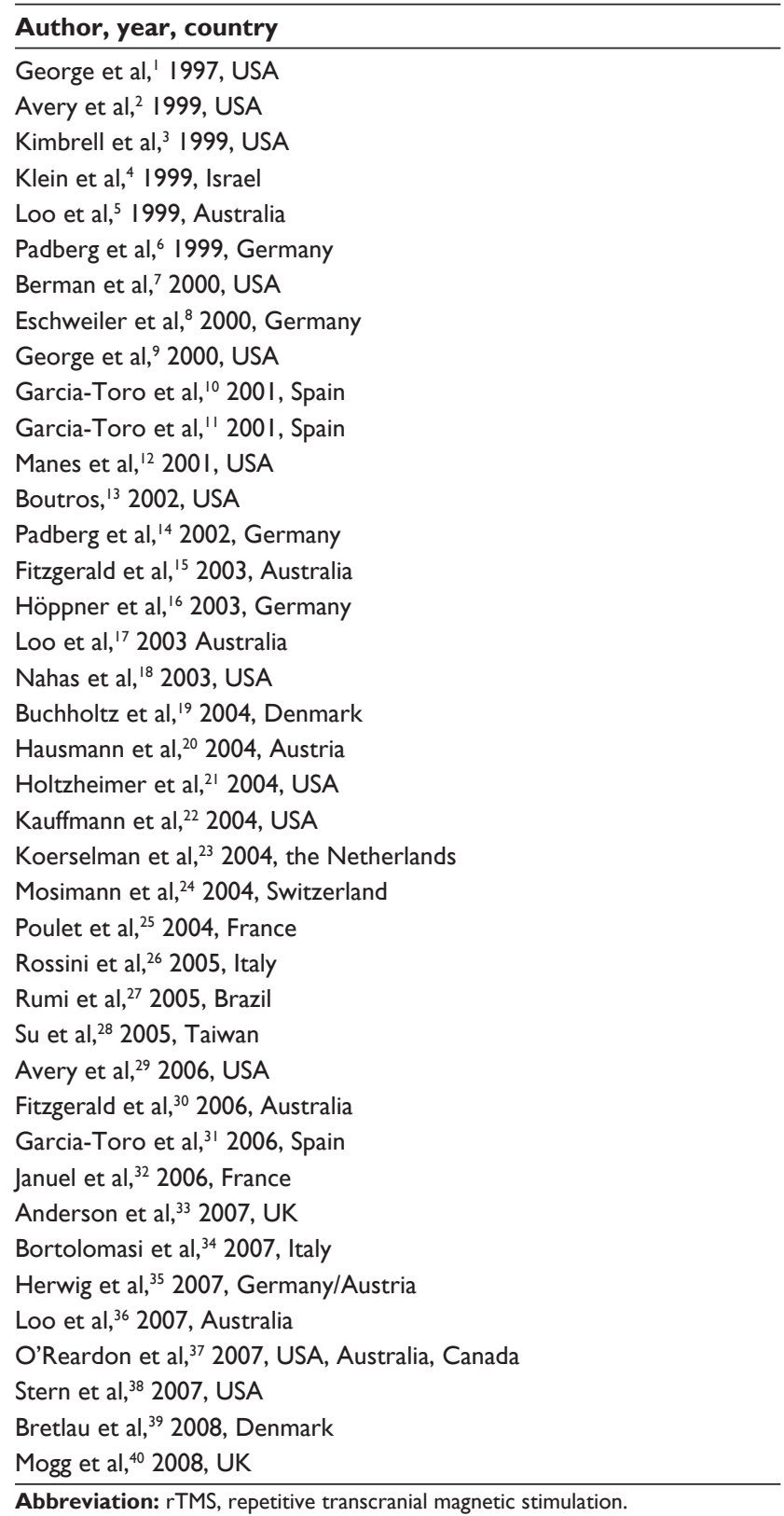

Table S2 $A$ list of $\mathrm{N}=50$ studies on the association between rTMS and depression assessed in full-length and reasons for exclusion from the current meta-analysis

\begin{tabular}{|c|c|}
\hline Author, year & Included/reason for exclusion \\
\hline Aguirre et al, ${ }^{41} 201 \mathrm{l}$ & $\begin{array}{l}\text { Included (additional data provided } \\
\text { by authors) }\end{array}$ \\
\hline \multirow[t]{2}{*}{ Avery et al, ${ }^{42} 2007$} & No new data (data from \\
\hline & Avery et al, ${ }^{29}$ 2006) \\
\hline Baeken et al, ${ }^{43} 2010$ & Cross-over design, only one session \\
\hline Bakim et al, ${ }^{44} 2012$ & Included \\
\hline \multirow[t]{2}{*}{ Bares et $\mathrm{al}^{45} 2009$} & No sham (rTMS and placebo \\
\hline & $\begin{array}{l}\text { medication versus sham and } \\
\text { venlafaxine) }\end{array}$ \\
\hline Blumberger et al, ${ }^{46} 2012$ & Included \\
\hline Brakemeier et al, ${ }^{47} 2007$ & No sham \\
\hline Brakemeier et al, ${ }^{48} 2008$ & No sham \\
\hline Chen et $\mathrm{al}^{49}{ }^{49} 2013$ & Included \\
\hline Cohen et al,,$^{50} 2009$ & No sham \\
\hline Dell'Osso et al, 2009 & No sham \\
\hline Fitzgerald et al, ${ }^{52} 2012$ & Included \\
\hline Furtado et al,,$^{53} 2012$ & No sham \\
\hline Galletly et al, ${ }^{54} 2012$ & No sham \\
\hline George et al, ${ }^{55} 2010$ & Included \\
\hline Hadley et al, ${ }^{56} 2011$ & No sham \\
\hline He et al, ${ }^{57} 201 \mathrm{I}$ & $\begin{array}{l}\text { Included (additional data provided } \\
\text { by authors) }\end{array}$ \\
\hline \multirow[t]{2}{*}{ Herbsman et al, ${ }^{58} 2009$} & No new data (data from \\
\hline & Avery et al, ${ }^{29} 2006$ ) \\
\hline Hernández-Ribas et al, ${ }^{59} 2013$ & Included \\
\hline \multirow[t]{2}{*}{ Herwig et al, ${ }^{60} 2010$} & No new data (data from \\
\hline & Herwig et al, ${ }^{35} 2007$ ) \\
\hline \multirow[t]{2}{*}{ Höppner et al,$^{61} 2010$} & No new data (data from \\
\hline & Herwig et al,,$^{35}$ 2007) \\
\hline Hoy et al, ${ }^{62} 2012$ & No sham \\
\hline Huang et al, ${ }^{63} 2008$ & No sham \\
\hline Huang et al, ${ }^{64} 2012$ & Included \\
\hline \multirow[t]{2}{*}{ Jacob et al,,$^{65} 2008$} & Inadequate data reported \\
\hline & (SD values missing on Figure I) \\
\hline \multirow[t]{2}{*}{ Kozel et al, ${ }^{66} 2011$} & No new data (data from \\
\hline & O'Reardon et al,,$^{37}$ 2007) \\
\hline Kreuzer et al, ${ }^{67} 2012$ & rTMS after sleep deprivation \\
\hline Lingeswaran et al, ${ }^{68} 201 \mathrm{I}$ & Included \\
\hline
\end{tabular}

(Continued) 
Table S2 (Continued)

Author, year

Lisanby et al, ${ }^{69} 2009$

Myczkowski et al, ${ }^{70} 2012$

Nongpiur et al, ${ }^{71} 201 \mathrm{I}$

Paillère Martinot et al, ${ }^{72} 2010$

Pallanti et al, ${ }^{73} 2010$

Peng et al, ${ }^{74} 2012$

Ray et al, ${ }^{75} 201 \mathrm{I}$

Rosenquist et al, ${ }^{76}$

2013

Schrijvers et al, ${ }^{77} 2012$

Schutter et al, ${ }^{78} 2009$

Schutter et al, ${ }^{79} 2010$

Simpson et al, ${ }^{80} 2009$

Spampinato et al, ${ }^{81}$

2013

Speer et al, 2009

Speer et al, ${ }^{83}$

2013

Tamas et al, ${ }^{84} 2007$

Triggs et al, ${ }^{85} 2010$

Trojak et al, ${ }^{86} 201 \mathrm{l}$

Ullrich et al, ${ }^{87} 2012$

Zarkowski et al, ${ }^{88}$

2009

Zheng et al, ${ }^{89} 2010$

Zheng et al, ${ }^{90} 2010$
Included/reason for exclusion

No new data (data from

O'Reardon et al, ${ }^{37}$ 2007)

Depression secondary to birth

(postpartum depression)

No sham (primed all conditions

with right I Hz stimulation)

Included (additional data provided

by authors)

Included (week 3 data extrapolated

from Figure I)

Included

Included

No new data (data from

O'Reardon et al, ${ }^{37}$ 2007)

No sham (one single sham session

followed by active treatment)

DLPFC not stimulated (parietal

cortex stimulated)

No new data (data from

Schutter et al, ${ }^{78}$ 2009)

No new data (data from

O'Reardon et al, ${ }^{37}$ 2007)

Included

Inadequate data reported (baseline scores/group missing)

Included

Inadequate data reported (HAMD

scores missing)

Included

Case study

No sham (sham was the active leftslow stimulation of the DLPFC)

No sham

No new data (same cases as in

Zheng et al, ${ }^{90}$ 2010)

Included

Note: $A$ total of $\mathrm{N}=18 / 50$ studies were included in the final meta-analysis.

Abbreviations: DLPFC, dorsolateral prefrontal cortex; HAMD, Hamilton

Depression Rating Scale; rTMS, repetitive transcranial magnetic stimulation; SD, standard deviation; 
Author, year

George et al, 1997 Avery et al, ${ }^{2} 1999$ Kimbrell et al, ${ }^{3} 1999$ all Klein et al, ${ }^{4} 1999$ Loo et al, ${ }^{5} 1999$ Padberg et al, ${ }^{6} 1999$ all Berman et al, ${ }^{7} 2000$ Eschweiler et al, ${ }^{8} 2000$ all George et al, ${ }^{9} 2000$ all Garcia-Toro et al, ${ }^{10} 2001$ Garcia-Toro et al, ${ }^{11} 2001$ Manes et al, ${ }^{12} 2001$ Boutros, ${ }^{13} 2002$ Padberg et al, ${ }^{14} 2002$ Fitzgerald et al, 152003 all Höppner et al, ${ }^{16} 2003$ Loo et al, ${ }^{17} 2003$ Buchholtz et al, ${ }^{19} 2004$ Hausmann et al, ${ }^{20} 2004$ Holtzheimer et al, ${ }^{21} 2004$ Kauffmann et al, ${ }^{22} 2004$ Koerselman et al, ${ }^{23} 2004$ Mosimann et al,,$^{24} 2004$ Poulet et al, ${ }^{25} 2004$ Rossini et al, ${ }^{26} 2005$ Rumi et al, ${ }^{27} 2005$ Su et al, ${ }^{28} 2005$ all Avery et al, ${ }^{29} 2006$ Fitzgerald et al, ${ }^{30} 2006$ Garcia-Toro et al, ${ }^{31} 2006$ Januel et al, ${ }^{32} 2006$ Anderson et al, ${ }^{33} 2007$ Bortolomasi et al, ${ }^{34} 2007$ Herwig et al, ${ }^{35} 2007$ Loo et al, ${ }^{36} 2007$ O'Reardon et al, ${ }^{37} 2007$ Stern et al, ${ }^{38} 2007$ all Bretlau et al, ${ }^{39} 2008$ Mogg et al, ${ }^{40} 2008$ George et al, ${ }^{55} 2010$ Paillère Martinot et $\mathrm{al}^{72} 2010$ Pallanti et al, ${ }^{73} 2010$ Triggs et al, ${ }^{85} 2010$ all Zheng et al, ${ }^{90} 2010$ Aguirre et al, ${ }^{41} 2011$ He et al, ${ }^{57} 2011$ Lingeswaran et al, ${ }^{68} 2011$ Ray et al, ${ }^{75} 2011$ Bakim et al, ${ }^{44} 2012$ Blumberger et al, ${ }^{46} 2012$ Fitzgerald et al, ${ }^{54} 2012$ Huang et al, ${ }^{64} 2012$ Peng et al, ${ }^{74} 2012$
Chen et al 492013 Hernández-Ribas et al,,$^{59} 2013$ Spampinato et al, ${ }^{81} 2013$ Speer et al ${ }^{83} 2013$ all

\begin{tabular}{|c|c|c|c|c|}
\hline \multirow[t]{2}{*}{ Outcome } & \multicolumn{4}{|c|}{ Statistics for each study } \\
\hline & $\begin{array}{l}\text { Std diff } \\
\text { in means }\end{array}$ & $\begin{array}{l}\text { Lower } \\
\text { s limit }\end{array}$ & $\begin{array}{c}\text { Upper } \\
\text { limit }\end{array}$ & \\
\hline MD & -1.44 & -2.73 & -0.16 & 0.02 \\
\hline ombined & -0.50 & -2.23 & 1.23 & \\
\hline MD & -0.4 & -1.75 & 86 & 50 \\
\hline mbined & -0.75 & -1.24 & -0.25 & .003 \\
\hline mbined & & & & \\
\hline AMD & -0.58 & & 42 & \\
\hline AMD & -1.21 & -2.17 & -0.26 & 013 \\
\hline mbined & -135 & -2.62 & -0.08 & \\
\hline (MR & -0.70 & & 08 & \\
\hline ned & -0.63 & -1.31 & 05 & 0.071 \\
\hline mbined & -0.44 & -1.29 & & 0.309 \\
\hline MMD & & & & \\
\hline AMD & -0 & -1.20 & 70 & 06 \\
\hline & -0 . & -1.92 & -0.06 & 0.038 \\
\hline & -0 . & & & \\
\hline ed & & & & \\
\hline $\mathrm{mt}$ & -0 & & 18 & 787 \\
\hline 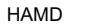 & & -0 & & \\
\hline & & & & \\
\hline & -0 & & 33 & 318 \\
\hline & -0 & & & \\
\hline M & 0 & & & \\
\hline AM & -0 & -0 & & \\
\hline & & & & \\
\hline & & & & \\
\hline & -0 & -1 & & \\
\hline$A D$ & -1 & -1 & $-c$ & 0.000 \\
\hline & -1 & -1 & & \\
\hline & -0 . & -1 & -0 & \\
\hline & -0 & -1 & & 0.075 \\
\hline & & -1 & & 86 \\
\hline & -1 & -2.46 & & \\
\hline & & & & \\
\hline & -1 & -2 & $-c$ & 20 \\
\hline & - & & & \\
\hline & & & & \\
\hline & -0 & -0 & -0 & 0.009 \\
\hline M & 1. & -2 & -0.74 & 0.000 \\
\hline & & & & \\
\hline & ( & -0 & & \\
\hline & - & & & \\
\hline & & & & 0260 \\
\hline & -1 & -2 & & \\
\hline & d & -0 & & \\
\hline & & -2 & -1 & 0 \\
\hline AIVI & 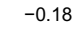 & -0 & & \\
\hline & & & & \\
\hline & & & & \\
\hline IV & -2 . & -3.58 & -1.86 & 0.000 \\
\hline & -0 & & & \\
\hline & & & & \\
\hline ed & & -1.03 & 6 & 0.227 \\
\hline & & & & \\
\hline & & -3 & -1.49 & \\
\hline 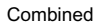 & & -0 & 30 & 0.427 \\
\hline & & & & \\
\hline ed & -2.04 & -3.07 & -1.00 & 0.000 \\
\hline ת & & & & \\
\hline & & & -0 & 0 \\
\hline
\end{tabular}

Std diff in means and $95 \% \mathrm{Cl}$

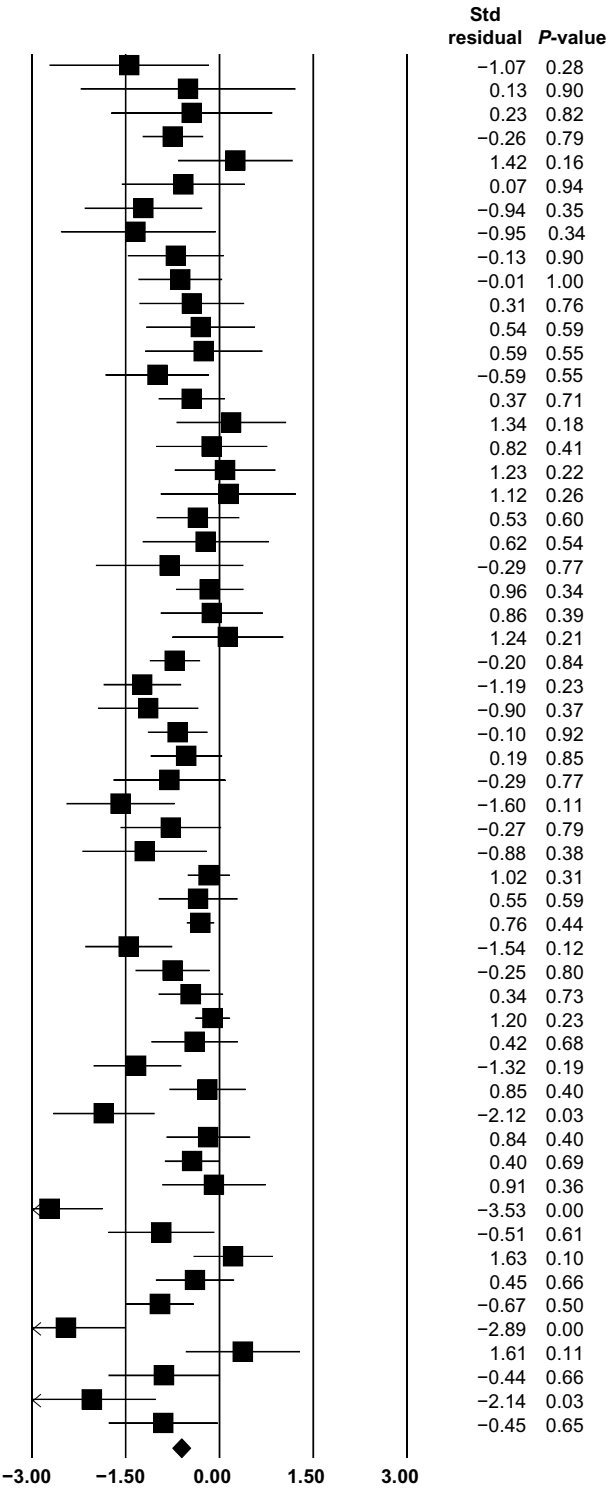

rTMS effective sham effective

Figure SI Random-effects meta-analysis of $\mathrm{N}=58$ studies with standardized residuals and their $P$-values.

Notes: "All" indicates that rTMS was administered using different properties into different subgroups of patients in a study and the depression scores for such subgroups were combined. "Combined" indicates that more than one depression scale was used in a study and the effect sizes according to the multiple scales were combined). According to the $P$-values, 4/I8 "new" studies were classified as outliers: Zheng et al 2010, ${ }^{90}$ Ray et al 201 I, ${ }^{75}$ Peng et al $2012,{ }^{74}$ and Spampinato et al $2013 .{ }^{81}$ These studies were excluded from all subsequent analyses.

Abbreviations: $\mathrm{Cl}$, confidence interval; HAMD, Hamilton Depression Rating Scale; MADRS, Montgomery Åsberg Depression Rating Scale; rTMS, repetitive transcranial magnetic stimulation; Std diff, standardized mean difference d; Std, standardized. 
Group by

Outliers

Outlier

Study

Overall
Statistics for each study

Std diff Standard Lower Upper

in means error limit limit $P$-value

$\begin{array}{lllll}-2.26 & 0.232 & -2.72 & -1.81 & 0.000 \\ -0.51 & 0.059 & -0.63 & -0.39 & 0.000 \\ -0.62 & 0.058 & -0.73 & -0.51 & 0.000\end{array}$

Std diff in means and $95 \% \mathrm{Cl}$

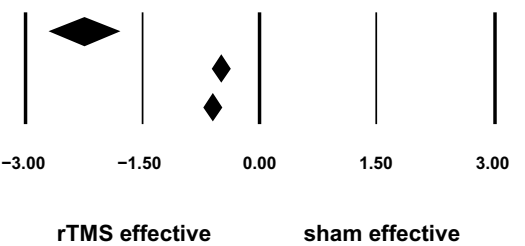

Figure S2 Forest plot showing the comparison of the $\mathrm{N}=4$ outliers with $\mathrm{N}=54$ studies.

Notes: Subgroup analysis using the mixed-effects model revealed that the overall mean weighted effect size $d$ was significantly higher in the $\mathrm{N}=4$ outlier studies ( $d=-2.26$ ) compared to the $\mathrm{N}=54$ studies $(d=-0.5 \mathrm{I})$ : $Q(d f \mathrm{I})=58.3, P<0.00 \mathrm{I}$. The variability of the weighted effect sizes was high among the $\mathrm{N}=4$ outlier studies $(\mathrm{SEM}=0.23)$ compared to the $\mathrm{N}=54$ studies (SEM $=0.06$ ).

Abbreviations: $\mathrm{Cl}$, confidence interval; rTMS, repetitive transcranial magnetic stimulation; SEM, standard error of mean; Std diff, standardized mean difference $d$. 


\begin{tabular}{|c|c|c|c|c|c|c|c|}
\hline \multirow[t]{2}{*}{ Author, year } & \multirow[t]{2}{*}{ Outcome } & \multicolumn{4}{|c|}{ Statistics for each study } & \multicolumn{2}{|c|}{ Sample size } \\
\hline & & $\begin{array}{c}\text { Std diff } \\
\text { in means }\end{array}$ & $\begin{array}{c}\text { Lower } \\
\text { limit }\end{array}$ & $\begin{array}{c}\text { Upper } \\
\text { limit }\end{array}$ & $P$-value & Sham & rTMS \\
\hline George et al, ${ }^{1} 1997$ & HAMD & -1.44 & -2.73 & -0.16 & 0.028 & 5 & 7 \\
\hline Avery et al, ${ }^{2} 1999$ & Combined & -0.50 & -2.23 & 1.23 & 0.572 & 2 & 4 \\
\hline Kimbrell et al, ${ }^{3} 1999$ all & HAMD & -0.44 & -1.75 & 0.86 & 0.503 & 3 & 10 \\
\hline Klein et al, ${ }^{4} 1999$ & Combined & -0.75 & -1.24 & -0.25 & 0.003 & 32 & 35 \\
\hline Loo et al, ${ }^{5} 1999$ & Combined & 0.25 & -0.67 & 1.18 & 0.592 & 9 & 9 \\
\hline Padberg et al, ${ }^{6} 1999$ all & HAMD & -0.58 & -1.57 & 0.42 & 0.258 & 6 & 12 \\
\hline $\begin{array}{l}\text { Berman et al, }{ }^{7} 2000 \\
\text { Eschweiler et al, }{ }^{8} 2000 \text { all }\end{array}$ & $\begin{array}{l}\text { HAMD } \\
\text { Combined }\end{array}$ & $\begin{array}{l}-1.21 \\
-1.35\end{array}$ & $\begin{array}{l}-2.17 \\
-2.62\end{array}$ & $\begin{array}{l}-0.26 \\
-0.08\end{array}$ & $\begin{array}{l}0.013 \\
0.038\end{array}$ & $\begin{array}{c}10 \\
5\end{array}$ & $\begin{array}{c}10 \\
7\end{array}$ \\
\hline George et al, ${ }^{9} 2000$ all & HAMD & -0.70 & -1.48 & 0.08 & 0.080 & 10 & 20 \\
\hline Garcia-Toro et al, ${ }^{10} 2001$ & Combined & -0.63 & -1.31 & 0.05 & 0.071 & 18 & 17 \\
\hline Garcia-Toro et al, ${ }^{11} 2001$ & $\begin{array}{l}\text { Combined } \\
\text { HAMD }\end{array}$ & $\begin{array}{l}-0.44 \\
-0.30\end{array}$ & -1.29 & 0.41 & & 11 & $\begin{array}{l}11 \\
10\end{array}$ \\
\hline Boutros, ${ }^{13} 2002$ & HAMD & -0.25 & -1.20 & 0.70 & 0.606 & 7 & 11 \\
\hline Padberg et al, ${ }^{14} 2002$ & Combined & -0.99 & -1.92 & -0.06 & 0.038 & 10 & 10 \\
\hline Fitzgerald et al, ${ }^{15} 2003$ all & Combined & -0.44 & -0.99 & 0.10 & 0.110 & 20 & 40 \\
\hline Höppner et al, ${ }^{16} 2003$ & Combined & 0.19 & -0.70 & 1.08 & 0.676 & 10 & 10 \\
\hline Loo et $\mathrm{al}^{17}{ }^{17} 2003$ & Combined & -0.12 & -1.03 & 0.78 & 0.787 & 10 & 9 \\
\hline Nahas et al, ${ }^{18} 2003$ & HAMD & 0.09 & -0.73 & 0.91 & 0.828 & 12 & 11 \\
\hline Buchholtz et al, ${ }^{19} 2004$ & HAMD & 0.14 & -0.95 & 1.24 & 0.796 & 7 & 6 \\
\hline Hausmann et $a l,,^{20} 2004$ & Combined & -0.34 & -1.02 & 0.33 & 0.318 & 13 & 25 \\
\hline $\begin{array}{l}\text { Holtzheimer et al, }{ }^{21} 2004 \\
\text { Kauffmann et al, } 22004\end{array}$ & $\begin{array}{l}\text { Combined } \\
\text { HAMD }\end{array}$ & $\begin{array}{l}-0.22 \\
-0.84\end{array}$ & $\begin{array}{l}-1.24 \\
-2.03\end{array}$ & $\begin{array}{l}0.80 \\
0.36\end{array}$ & $\begin{array}{l}0.674 \\
0.171\end{array}$ & $\begin{array}{l}8 \\
5\end{array}$ & $\begin{array}{l}7 \\
7\end{array}$ \\
\hline Koerselman et al, ${ }^{23} 2004$ & HAMD & -0.15 & -0.70 & 0.40 & 0.584 & 25 & 26 \\
\hline Mosimann et al, ${ }^{24} 2004$ & Combined & -0 & -0.95 & 0.71 & 0.774 & 9 & 15 \\
\hline Poulet et al, ${ }^{25} 2004$ & Combined & 0.13 & -0.77 & 1.04 & 0.772 & 9 & 10 \\
\hline Rossini et al, ${ }^{26} 2005$ & HAMD & -0.71 & -1.13 & -0.30 & 0.001 & 47 & 49 \\
\hline Rumi et al, ${ }^{27} 2005$ & MADRS & -1.23 & -1.87 & -0.60 & 0.000 & 24 & 22 \\
\hline Su et al, ${ }^{28} 2005$ all & Combined & -1.14 & -1.95 & -0.33 & 0.006 & 10 & 20 \\
\hline Avery et al, ${ }^{29} 2006$ & Combined & -0.67 & -1.16 & -0.18 & 0.007 & 33 & 35 \\
\hline Fitzgerald et al, ${ }^{30} 2006$ & Combined & -0.53 & -1.11 & 0.05 & 0.075 & 22 & 25 \\
\hline Garcia-Toro et al, ${ }^{31} 2006$ & HAMD & 80 & -1.71 & 0.11 & 86 & 10 & 10 \\
\hline Januel et al, ${ }^{32} 2006$ & HAMD & -1.58 & -2.46 & -0.71 & 0.000 & 16 & 11 \\
\hline Anderson et al, ${ }^{33} 2007$ & MADRS & -0.78 & -1.60 & 0.04 & 0.063 & 14 & 11 \\
\hline Bortolomasi et al, ${ }^{34} 2007$ & Combined & -1.20 & -2.20 & -0.19 & 0.020 & 7 & 12 \\
\hline Herwig et al, ${ }^{35} 2007$ & Combined & -0.17 & -0.54 & 0.19 & 0.355 & 59 & 57 \\
\hline Loo et al, ${ }^{36} 2007$ & Combined & -0.34 & -0.98 & 0.30 & 0.298 & 19 & 19 \\
\hline O'Reardon et al ${ }^{37} 2007$ & Combined & -0.30 & -0.53 & -0.08 & 0.009 & 146 & 155 \\
\hline Stem et al, ${ }^{38} 2007$ all & HAMD & -1.45 & -2.16 & -0.74 & 0.000 & 14 & 29 \\
\hline Bretlau et al, ${ }^{39} 2008$ & HAMD & -0.75 & -1.35 & -0.15 & 0.015 & 23 & 22 \\
\hline Mogg et al al, ${ }^{40} 2008$ & Combined & -0.46 & -0.99 & 0.07 & 0.087 & 29 & 28 \\
\hline George et al, ${ }^{55} 2010$ & Combined & -0.11 & -0.40 & 0.18 & 0.456 & 94 & 88 \\
\hline Paillère Martinot et al, ${ }^{72} 2010$ & Combined & -0.40 & -1.10 & 0.31 & 0.269 & 14 & 18 \\
\hline Pallanti et al, ${ }^{73} 2010$ & HAMD & -1.33 & -2.01 & -0.64 & 0.000 & 20 & 20 \\
\hline Triggs et $a l,{ }^{85} 2010$ all & Combined & -0.19 & -0.81 & 0.43 & 0.548 & 14 & 34 \\
\hline Aguirre et al, ${ }^{41} 2011$ & HAMD & -0.18 & -0.86 & 0.50 & 0.605 & 15 & 19 \\
\hline He et al, ${ }^{57} 2011$ & HAMD & -0.44 & -0.88 & 0.01 & 0.054 & 43 & 37 \\
\hline Lingeswaran et al, ${ }^{68} 2011$ & Combined & -0.09 & -0.93 & 0.75 & 0.836 & 14 & 9 \\
\hline Bakim et al, ${ }^{44} 2012$ & Combined & -0.93 & -1.79 & -0.07 & 0.035 & 12 & 11 \\
\hline Blumberger et al, ${ }^{46} 2012$ & HAMD & 0.22 & -0.43 & 0.87 & 0.505 & 18 & 19 \\
\hline Fitzgerald et al, ${ }^{54} 2012$ & Combined & -0.39 & -1.03 & 0.24 & 0.227 & 18 & 21 \\
\hline Huang et al, ${ }^{64} 2012$ & Combined & -0.95 & -1.51 & -0.40 & 0.001 & 28 & 28 \\
\hline Chen et al, ${ }^{64} 2013$ & Combined & 0.38 & -0.55 & 1.30 & 0.427 & 10 & 10 \\
\hline Hernández-Ribas et al, ${ }^{59} 2013$ & HAMD & -0.89 & -1.79 & 0.01 & 0.052 & 11 & 10 \\
\hline Speer et al, ${ }^{83} 2013$ all & HAMD & -0.90 & -1.78 & -0.01 & 0.047 & 8 & 16 \\
\hline & & -0.51 & -0.63 & -0.39 & 0.000 & & \\
\hline
\end{tabular}

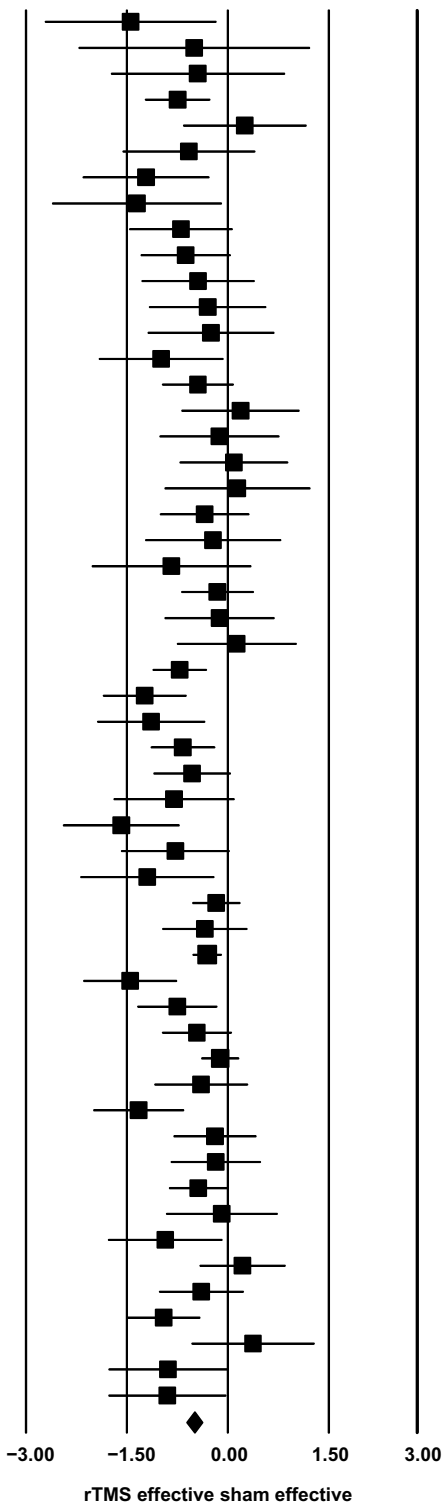

Figure S3 Random-effects meta-analysis of $\mathrm{N}=54$ studies.

Notes: "All" indicates that rTMS was administered using different properties into different subgroups of patients in a study and the depression scores for such subgroups were combined. "Combined" indicates that more than one depression scale was used in a study and the effect sizes according to the multiple scales were combined). The mean number of patients per group was used in the final calculations if patients dropped out throughout the study between baseline and final sessions.

Abbreviations: Cl, confidence interval; HAMD, Hamilton Depression Rating Scale; MADRS, Montgomery Åsberg Depression Rating Scale; rTMS, repetitive transcranial magnetic stimulation; Std diff, standardized mean difference $d$. 


\begin{tabular}{|c|c|c|c|c|c|}
\hline \multirow[t]{2}{*}{ Author, year } & \multirow[t]{2}{*}{ Outcome } & \multicolumn{4}{|c|}{ Statistics with study removed } \\
\hline & & Point & $\begin{array}{l}\text { Lower } \\
\text { limit }\end{array}$ & $\begin{array}{l}\text { Upper } \\
\text { limit }\end{array}$ & $P$-value \\
\hline George et al, ${ }^{1} 1997$ & HAMD & -0.50 & -0.62 & -0.39 & 0.000 \\
\hline Avery et al, ${ }^{2} 1999$ & Combined & -0.51 & -0.63 & -0.39 & 0.000 \\
\hline Kimbrell et al, ${ }^{3} 1999$ all & HAMD & -0.51 & -0.63 & -0.39 & 0.000 \\
\hline Klein et al, ${ }^{4} 1999$ & Combined & -0.50 & -0.62 & -0.39 & 0.000 \\
\hline Loo et al, ${ }^{5} 1999$ & Combined & -0.52 & -0.64 & -0.40 & 0.000 \\
\hline Padberg et al, ${ }^{6} 1999$ all & HAMD & -0.51 & -0.63 & -0.39 & 0.000 \\
\hline Berman et al, ${ }^{7} 2000$ & HAMD & -0.50 & -0.62 & -0.38 & 0.000 \\
\hline Eschweiler et al, ${ }^{8} 2000$ all & Combined & -0.50 & -0.62 & -0.39 & 0.000 \\
\hline George et al, ${ }^{9} 2000$ all & HAMD & -0.51 & -0.63 & -0.39 & 0.000 \\
\hline Garcia-Toro et al, ${ }^{10} 2001$ & Combined & -0.51 & -0.62 & -0.39 & 0.000 \\
\hline Garcia-Toro et al, ${ }^{11} 2001$ & Combined & -0.51 & -0.63 & -0.39 & 0.000 \\
\hline Manes et al, ${ }^{12} 2001$ & HAMD & -0.51 & -0.63 & -0.40 & 0.000 \\
\hline Boutros, ${ }^{13} 2002$ & HAMD & -0.51 & -0.63 & -0.40 & 0.000 \\
\hline Padberg et al, ${ }^{14} 2002$ & Combined & -0.50 & -0.62 & -0.39 & 0.000 \\
\hline Fitzgerald et al, ${ }^{15} 2003$ all & Combined & -0.51 & -0.63 & -0.39 & 0.000 \\
\hline Höppner et al, ${ }^{16} 2003$ & Combined & -0.52 & -0.64 & -0.40 & 0.000 \\
\hline Loo et al, ${ }_{17}^{17} 2003$ & Combined & -0.52 & -0.63 & -0.40 & 0.000 \\
\hline Nahas et al, ${ }^{18} 2003$ & HAMD & -0.52 & -0.64 & -0.40 & 0.000 \\
\hline Buchholtz et al, ${ }^{19} 2004$ & HAMD & -0.52 & -0.63 & -0.40 & 0.000 \\
\hline Hausmann et al, ${ }^{20} 2004$ & Combined & -0.51 & -0.63 & -0.40 & 0.000 \\
\hline Holtzheimer et al, ${ }^{21} 2004$ & Combined & -0.51 & -0.63 & -0.40 & 0.000 \\
\hline Kauffmann et al, ${ }^{22} 2004$ & HAMD & -0.51 & -0.63 & -0.39 & 0.000 \\
\hline Koerselman et al ${ }^{23} 2004$ & HAMD & -0.52 & -0.64 & -0.40 & 0.000 \\
\hline Mosimann et al, ${ }^{24} 2004$ & Combined & -0.52 & -0.63 & -0.40 & 0.000 \\
\hline Poulet et al, ${ }^{25} 2004$ & Combined & -0.52 & -0.64 & -0.40 & 0.000 \\
\hline Rossini et al, ${ }^{26} 2005$ & HAMD & -0.50 & -0.62 & -0.38 & 0.000 \\
\hline Rumi et $\mathrm{al}{ }^{27} 2005$ & MADRS & -0.49 & -0.61 & -0.38 & 0.000 \\
\hline Su et al, ${ }^{28} 2005$ all & Combined & -0.50 & -0.62 & -0.38 & 0.000 \\
\hline Avery et al, ${ }^{29} 2006$ & Combined & -0.51 & -0.63 & -0.39 & 0.000 \\
\hline Fitzgerald et al, ${ }^{30} 2006$ & Combined & -0.51 & -0.63 & -0.39 & 0.000 \\
\hline Garcia-Toro et al, ${ }^{31} 2006$ & HAMD & -0.50 & -0.62 & -0.39 & 0.000 \\
\hline Januel et al, ${ }^{32} 2006$ & HAMD & -0.49 & -0.61 & -0.38 & 0.000 \\
\hline Anderson et al, ${ }^{33} 2007$ & MADRS & -0.51 & -0.62 & -0.39 & 0.000 \\
\hline Bortolomasi et al, ${ }^{34} 2007$ & Combined & -0.50 & -0.62 & -0.39 & 0.000 \\
\hline Herwig et al, ${ }^{35} 2007$ & Combined & -0.52 & -0.64 & -0.40 & 0.000 \\
\hline Loo et al, ${ }^{36} 2007$ & Combined & -0.51 & -0.63 & -0.40 & 0.000 \\
\hline O'Reardon et al, ${ }^{37} 2007$ & Combined & -0.52 & -0.64 & -0.40 & 0.000 \\
\hline Stem et al, ${ }^{38} 2007$ all & HAMD & -0.49 & -0.60 & -0.38 & 0.000 \\
\hline Bretlau et al, ${ }^{39} 2008$ & HAMD & -0.51 & -0.62 & -0.39 & 0.000 \\
\hline Mogg et al, ${ }^{40} 2008$ & Combined & -0.51 & -0.63 & -0.39 & 0.000 \\
\hline George et al, ${ }^{55} 2010$ & Combined & -0.53 & -0.64 & -0.41 & 0.000 \\
\hline Paillère Martinot et al, ${ }^{72} 2010$ & Combined & -0.51 & -0.63 & -0.39 & 0.000 \\
\hline Pallanti et al, ${ }^{73} 2010$ & HAMD & -0.49 & -0.60 & -0.38 & 0.000 \\
\hline Triggs et al, ${ }^{85} 2010$ all & Combined & -0.52 & -0.64 & -0.40 & 0.000 \\
\hline Aguirre et al, ${ }^{41} 2011$ & HAMD & -0.52 & -0.64 & -0.40 & 0.000 \\
\hline He et al, ${ }^{57} 2011$ & HAMD & -0.51 & -0.63 & -0.39 & 0.000 \\
\hline Lingeswaran et al, ${ }^{68} 2011$ & Combined & -0.52 & -0.63 & -0.40 & 0.000 \\
\hline Bakim et al, ${ }^{44} 2012$ & Combined & -0.50 & -0.62 & -0.39 & 0.000 \\
\hline Blumberger et al ${ }^{46} 2012$ & HAMD & -0.52 & -0.64 & -0.41 & 0.000 \\
\hline Fitzgerald et al, ${ }^{54} 2012$ & Combined & -0.51 & -0.63 & -0.39 & 0.000 \\
\hline Huang et al ${ }^{64} 2012$ & Combined & -0.50 & -0.61 & -0.38 & 0.000 \\
\hline Chen et al, ${ }^{64} 2013$ & Combined & -0.52 & -0.64 & -0.40 & 0.000 \\
\hline Hernández-Ribas et al, ${ }^{59} 2013$ & HAMD & -0.50 & -0.62 & -0.39 & 0.000 \\
\hline Speer et al, ${ }^{83} 2013$ all & HAMD & -0.50 & -0.62 & -0.39 & 0.000 \\
\hline & & -0.51 & -0.63 & -0.39 & 0.000 \\
\hline
\end{tabular}

Std diff in means $(95 \%$
Cl) with study removed

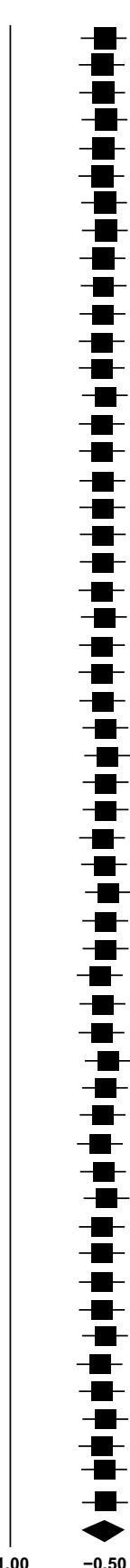

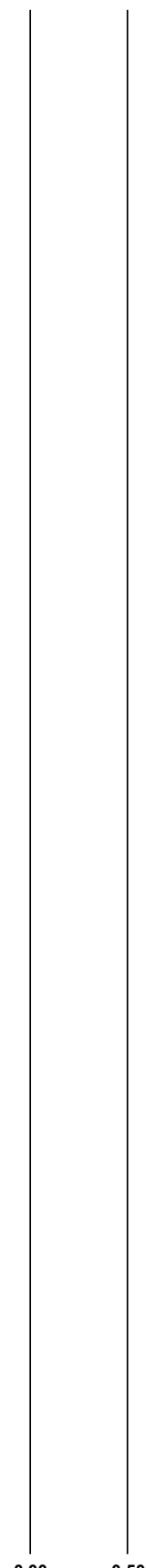

0.50

rTMS effective sham effective

Figure S4 One study removed analysis ( $\mathrm{N}=54$ studies).

Notes: "All" indicates that rTMS was administered using different properties into different subgroups of patients in a study and the depression scores for such subgroups were combined. "Combined" indicates that more than one depression scale was used in a study and the effect sizes according to the multiple scales were combined). "Point" refers to the overall mean weighted $d$ of all studies except for the study listed in each row.

Abbreviations: $\mathrm{Cl}$, confidence interval; HAMD, Hamilton Depression Rating Scale; MADRS, Montgomery Åsberg Depression Rating Scale; rTMS, repetitive transcranial magnetic stimulation; Std diff, standardized mean difference $d$. 


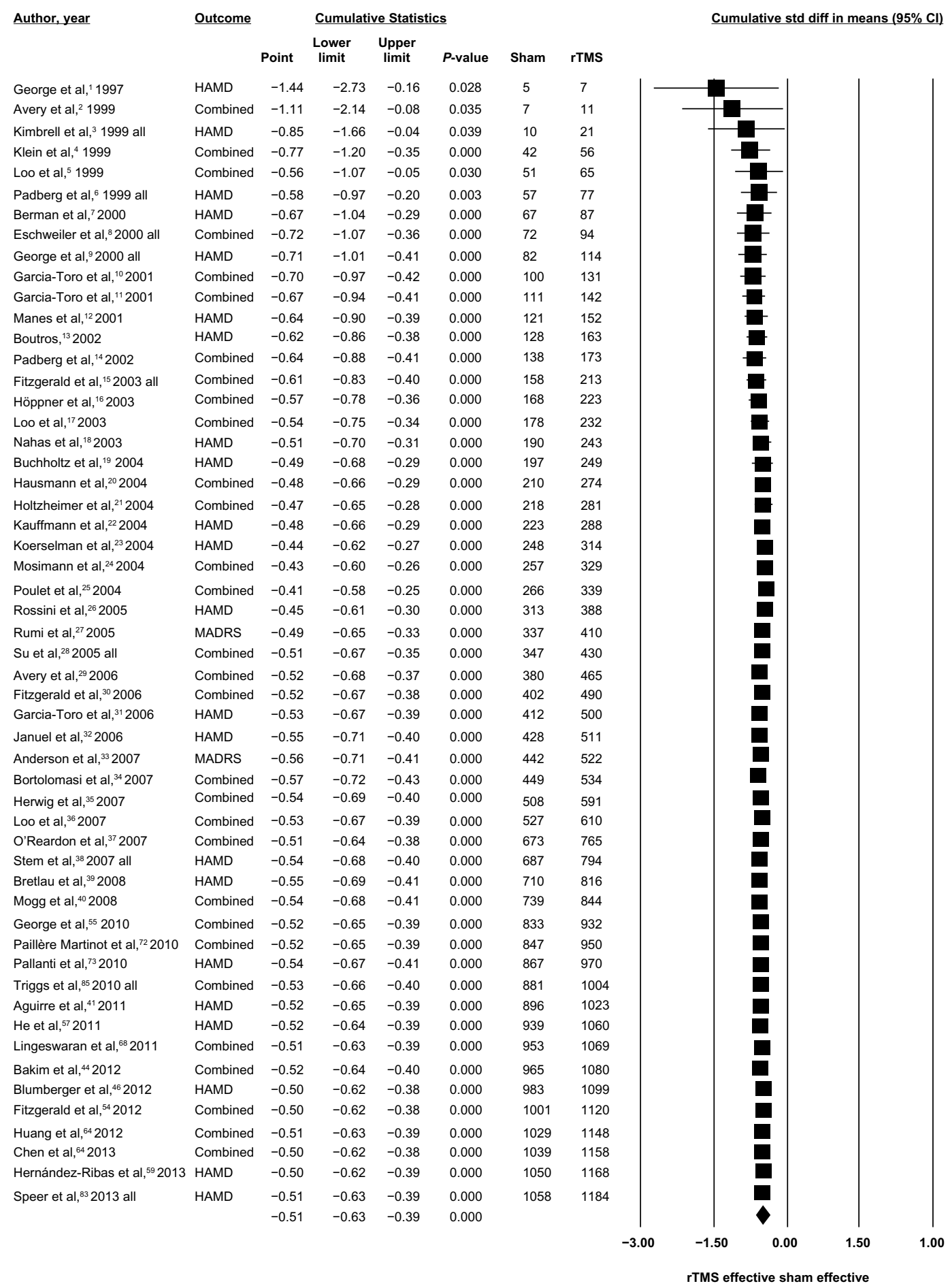

Figure S5 Cumulative meta-analysis ( $\mathrm{N}=54$ studies).

Notes: "All" indicates that rTMS was administered using different properties into different subgroups of patients in a study and the depression scores for such subgroups were combined. "Combined" indicates that more than one depression scale was used in a study and the effect sizes according to the multiple scales were combined). "Point" refers to the overall mean weighted $d$ of all studies before and including the study listed in each row.

Abbreviations: $\mathrm{Cl}$, confidence interval; HAMD, Hamilton Depression Rating Scale; MADRS, Montgomery Åsberg Depression Rating Scale; rTMS, repetitive transcranial magnetic stimulation; Std diff, standardized mean difference $d$. 
A

Regression of total stimuli on std diff in means

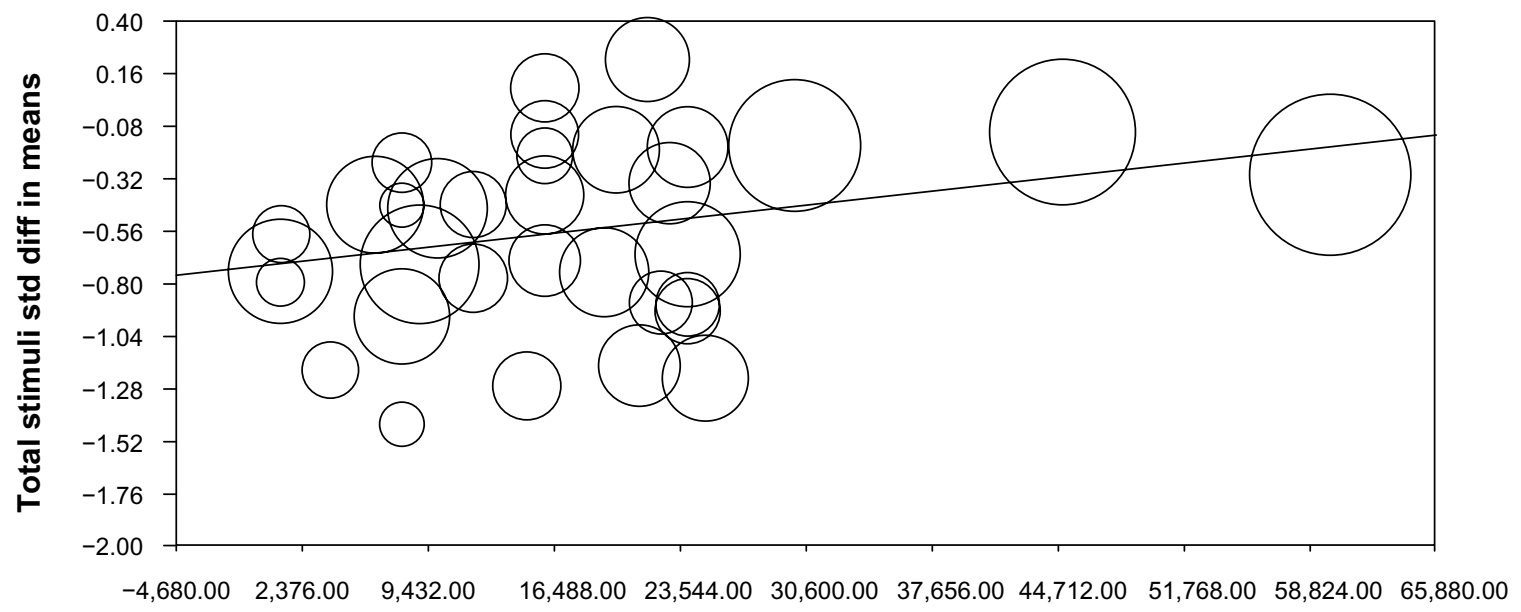

Total stiuli

B

Regression of total stimuli on std diff in means

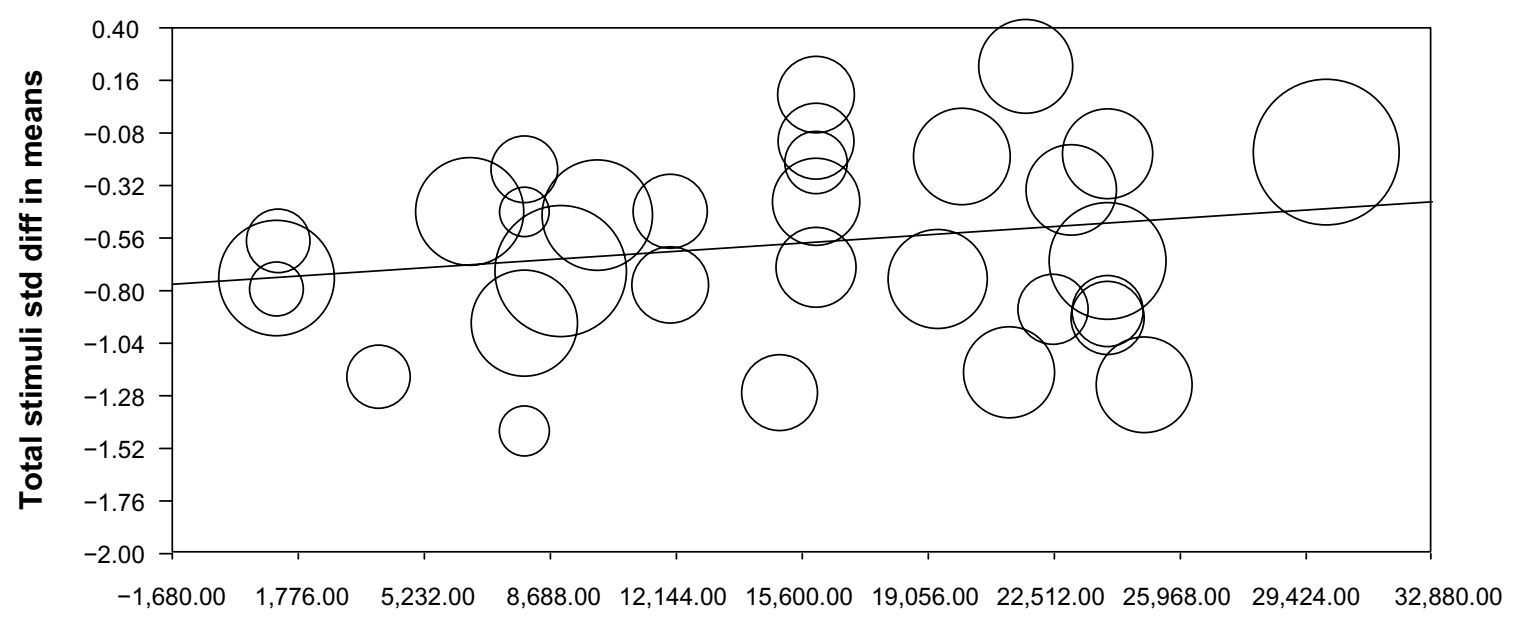

Total stimuli

Figure S6 Univariate meta-regression of the total stimuli/study on the effect size $d$ weighted according to the random-effects model.

Notes: Total stimuli $=$ stimuli/session $\times$ total number of sessions. $(\mathbf{A})$ The top figure shows the results of a significant meta-regression (slope $P=0.0$ I 5 ) in $\mathrm{N}=33$ studies. However, the significance of this regression was due to two largest RCTs by O'Reardon et al ${ }^{37}$ and George et al ${ }^{55}$ (depicted as two largest circles on the right-hand side of $(\mathbf{A})$. (B) These two RCTs are removed from the analysis in the bottom figure (slope, $P=0.208$ ).

Abbreviations: RCT, randomized controlled trial; std diff, standardized mean difference $d$. 


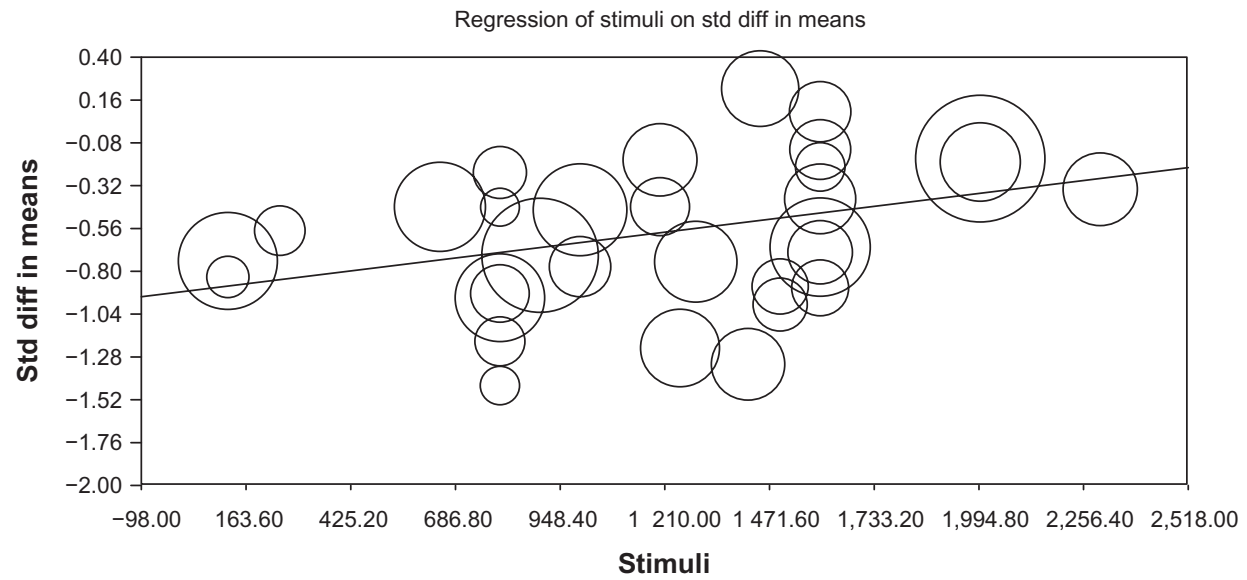

Figure S7 Univariate meta-regression of the stimuli/session on the effect size $d$ weighted according to the random-effects model (two largest RCTs removed). Notes: The slope of meta-regression conducted on $\mathrm{N}=3 \mathrm{I}$ studies remained positive and statistically significant $(P=0.018)$ following the removal of $\mathrm{O}$ 'Reardon et a ${ }^{37}$ and George et $\mathrm{al}^{55}$ studies.

Abbreviations: RCT, randomized controlled trial; std diff, standardized mean difference $d$.

Table S3 Location (country) where the $\mathrm{N}=54$ studies published from 1997 to August 2013 were conducted

\begin{tabular}{lll}
\hline Rank & Country & $\begin{array}{l}\text { Number } \\
\text { of studies }\end{array}$ \\
\hline I & USA & 16 \\
2 & Australia & 7 \\
3 & Spain & 6 \\
4 & Germany & 4 \\
5 & People's Republic of China, France, Italy & 3 each \\
6 & Austria, Canada, Denmark, UK & 2 each \\
7 & Brazil, India, the Netherlands, Switzerland, & I each \\
& Taiwan, Turkey & \\
\hline
\end{tabular}

Note: $\mathrm{N}$ does not add up to 54 because some studies were conducted in more than one country.

\section{References}

1. George M, Wassermann EM, Williams WE, et al. Mood improvement following daily left prefrontal repetitive transcranial magnetic stimulation in patients with depression: A placebo-controlled crossover trial. American Journal of Psychiatry. 1997;154:1752-1756.

2. Avery D, Claypoole K, Robinson L, et al. Repetitive transcranial magnetic stimulation in the treatment of medication-resistant depression: preliminary data. Journal of Nervous and Mental Disease. 1999;187(2):114-117.

3. Kimbrell T, Little J, Dunn R, et al. Frequency dependence of antidepressant response to left prefrontal repetitive transcranial magnetic stimulation (rTMS) as a function of baseline cerebral glucose metabolism. Biological Psychiatry. 1999;46:1603-1613.

4. Klein E, Kreinin I, Chistyakov A. Therapeutic efficacy of right prefrontal slow repetitive transcranial magnetic stimulation in major depression: A double blind controlled study. Archives of General Psychiatry. 1999;56:315-320.

5. Loo C, Mitchell P, Sachdev P, McDarmont B, Parker G, Gandevia S. Double-blind controlled investigation of transcranial magnetic stimulation for the treatment of resistant major depression. American Journal of Psychiatry. 1999;156:946-948.

6. Padberg F, Zwanzger P, Thoma H, et al. Repetitive transcranial magnetic stimulation (rTMS) in pharmacotherapy-refractory major depression: comparative study of fast, slow and sham rTMS. Psychiatry Research. 1999;88:163-171.
7. Berman R, Hoffman R, Narashima M, et al. A randomized clinical trial of repetitive transcranial magnetic stimulation in the treatment of major depression. Biological Psychiatry. 2000;47: 332-337.

8. Eschweiler G, Wegerer C, Schlotter W, et al. Left prefrontal activation predicts therapeutic effects of repetitive transcranial magnetic stimulation (rTMS) in major depression. Psychiatry Research: Neuroimaging Section. 2000;99:161-172.

9. George M, Nahas Z, Molloy M, et al. A controlled trial of daily left prefrontal cortex TMS for treating depression. Biological Psychiatry. 2000;48:962-970.

10. Garcia-Toro M, Mayol A, Arnillas H, et al. Modest adjunctive benefit with transcranial magnetic stimulation in medicationresistant depression. Journal of Affective Disorders. 2001;64(2-3): 271-275.

11. García-Toro M, Pascual-Leone A, Romera M, et al. Prefrontal repetitive transcranial magnetic stimulation as add on treatment in depression. Journal of Neurology, Neurosurgery and Psychiatry. 2001;71:546-548.

12. Manes F, Jorge R, Morcuende M, Yamada T, Paradiso S, Robinson R. A controlled study of repetitive transcranial magnetic stimulation as a treatment of depression in the elderly. International Psychogeriatrics. 2001;13(2):225-231.

13. Boutros N. Lack of a therapeutic effect of a 2-week sub-threshold transcranial magnetic stimulation course for treatment-resistant depression. Psychiatry Research. 2002;113(3):245-254.

14. Padberg F, Zwanzger P, Keck M, et al. Repetitive transcranial magnetic stimulation (rTMS) in major depression: relation between efficacy and stimulation intensity. Neuropsychopharmacology. 2002;27(4):638-645.

15. Fitzgerald P, Brown T, Marston N, Daskalakis Z, de Castella A, Kulkarni J. Transcranial magnetic stimulation in the treatment of depression: a double-blind, placebo-controlled trial. Archives of General Psychiatry. 2003;60:1002-1008.

16. Höppner J, Schulz M, Irmisch G, Mau R, Schläfke D, Richter J. Antidepressant efficacy of two different rTMS procedures: High frequency over left versus low frequency over right prefrontal cortex compared with sham stimulation. European Archives of Psychiatry and Clinical Neuroscience. 2003;253:103-109.

17. Loo C, Mitchell P, Croker V, et al. Double-blind controlled investigation of bilateral prefrontal transcranial magnetic stimulation for the treatment of resistant major depression. Psychological Medicine. 2003;33:33-40. 
18. Nahas Z, Kozel F, Li X, Anderson B, George M. Left prefrontal transcranial magnetic stimulation (rTMS) treatment of depression in bipolar affective disorder: a pilot study of acute safety and efficacy. Bipolar Disorder. 2003;5(1):40-47.

19. Buchholtz H, Videbech P, Clemmensen K, Sturlason R, Jensen H, Vestergaard P. Repetitive transcranial magnetic stimulation as add-on antidepressant treatment. The applicability of the method in a clinical setting. Nordic Journal of Psychiatry. 2004;58(6):455-457.

20. Hausmann A, Kemmler G, Walpoth M, et al. No benefit derived from repetitive transcranial magnetic stimulation in depression: a prospective, single-centre, randomised, double blind, sham-controlled "add on" trial. Journal of Neurology, Neurosurgery and Psychiatry. 2004;75(2):320-322.

21. Holtzheimer III P, Russo J, Claypoole K, Roy-Byrne P, Avery D. Shorter duration of depressive episode may predict response to repetitive transcranial magnetic stimulation. Depression and Anxiety. 2004;19:24-30.

22. Kauffmann C, Cheema M, Miller B. Slow right prefrontal transcranial magnetic stimulation as a treatment for medication-resistant depression: A double-blind, placebo-controlled study. Depression and Anxiety. 2004;19:59-62.

23. Koerselman F, Laman D, van Duijn H, van Duijn M, Willems M. A 3-month, follow-up, randomized, placebo-controlled study of repetitive transcranial magnetic stimulation in depression. Journal of Clinical Psychiatry. 2004;65:1323-1328.

24. Mosimann U, Schmitt W, Greenberg B, et al. Repetitive transcranial magnetic stimulation: a putative add-on treatment for major depression in elderly patients. Psychiatry Research. 2004;126:123-133.

25. Poulet E, Brunelin J, Boeuve C, et al. Repetitive transcranial magnetic stimulation does not potentiate antidepressant treatment. European Psychiatry. 2004;19:382-383.

26. Rossini D, Magri L, Lucca A, Giordani S, Smeraldi E, Zanardi R. Does rTMS hasten the response to escitalopram, sertraline, or venlafaxine in patients with major depressive disorder? A double-blind, randomized, sham-controlled trial. Journal of Clinical Psychiatry. 2005;66(12):1569-1575.

27. Rumi D, Gattaz W, Rigonatti S, et al. Transcranial magnetic stimulation accelerates the antidepressant effect of amitriptyline in severe depression: a double-blind placebo-controlled study. Biological Psychiatry. 2005;57:162-166

28. Su T, Huang C, Wei I. Add-on rTMS for medication-resistant depression:a randomized, double-blind, sham-controlled trial in Chinese patients. Journal of Clinical Psychiatry. 2005;66(7):930-937.

29. Avery D, Holtzheimer III P, Fawaz W, et al. A controlled study of repetitive transcranial magnetic stimulation in medication-resistant major depression. Biological Psychiatry. 2006;59:187-194.

30. Fitzgerald P, Benitez J, de Castella A, Daskalakis Z, Brown T, Kulkarni J. A randomized, controlled trial of sequestial bilateral repetitive transcranial magnetic stimulation for treatment-resistant depression. American Journal of Psychiatry. 2006;163:88-94.

31. Garcia-Toro M, Salva J, Daumal J, et al. High (20-Hz) and low (1-Hz) frequency transcranial magnetic stimulation as adjuvant treatment in medication-resistant depression. Psychiatry Research: Neuroimaging. 2006;146:53-57.

32. Januel D, Dumortier G, Verdon C, et al. A double-blind sham controlled study of right prefrontal repetitive transcranial magnetic stimulation (rTMS): Therapeutic and cognitive effect in medication free unipolar depression during 4 weeks. Progress In Neuro-Psychopharmacology and Biological Psychiatry. 2006;30:126-130.

33. Anderson I, Delvai N, Ashim B, et al. Adjunctive fast repetitive transcranial magnetic stimulation in depression. British Journal of Psychiatry. 2007;190:533-534.

34. Bortolomasi M, Minelli A, Fuggetta G, et al. Long-lasting effects of high frequency repetitive transcranial magnetic stimulation in major depressed patients. Psychiatry Research. 2007;150(2):181-186.

35. Herwig U, Fallgatter A, Hoppner J, et al. Antidepressant effects of augmentative transcranial magnetic stimulation. Randomised multicentre trial. British Journal of Psychiatry. 2007;191:441-448.
36. Loo C, Mitchell P, McFarquhar T, Malhi G, Sachdev P. A shamcontrolled trial of the efficacy and safety of twice-daily rTMS in major depression. Psychological Medicine. 2007;37:341-349.

37. O’Reardon J, Solvason H, Janicak P, et al. Efficacy and safety of transcranial magnetic stimulation in the acute treatment of major depression: A multisite randomized controlled trial. Biological Psychiatry. 2007;62:1208-1216.

38. Stern W, Tormos J, Press D, Pearlman C, Pascual-Leone A. Antidepressant effects of high and low frequency repetitive transcranial magnetic stimulation to the dorsolateral prefrontal cortex:a double-blind, randomized, placebo- controlled trial. Journal of Neuropsychiatry and Clinical Neurosciences. 2007;19(2):179-186.

39. Bretlau L, Lindberg L, Unden M, Dissing S, Bech P. Repetitive transcranial magnetic stimulation (rTMS) in combination with escitalopram in patients with treatment-resistant major depression. A double-blind, randomised, sham-controlled trial. Pharmacopsychiatry. 2008;41(2):41-47.

40. Mogg A, Pluck G, Eranti S, et al. A randomized controlled trial with 4-month follow-up of adjunctive repetitive transcranial magnetic stimulation of the left prefrontal cortex for depression. Psychological Medicine. 2008;38:323-333.

41. Aguirre I, Carretero B, Ibarra O, et al. Age predicts low-frequency transcranial magnetic stimulation efficacy in major depression. Journal of Affective Disorders. 2011;130(3):466-469.

42. Avery DH, Holtzheimer PE, 3rd, Fawaz W, et al. Transcranial magnetic stimulation reduces pain in patients with major depression: a sham-controlled study. The Journal of Nervous And Mental Disease. 2007:195(5):378-381.

43. Baeken C, De Raedt R, Vanderhasselt M-A, et al. A "hypersensitive" hypothalamic-pituitary-adrenal system could be indicative for a negative clinical high-frequency repetitive transcranial magnetic stimulation outcome in melancholic depressed patients. Brain Stimulation. 2010;3(1):54-57.

44. Bakim B, Uzun UE, Karamustafalioglu O, et al. The combination of antidepressant drug therapy and high-frequency repetitive transcranial magnetic stimulation in medication-resistant depression. Bulletin of Clinical Psychopharmacology. 2012;22(3):244-253.

45. Bares M, Kopecek M, Novak T, et al. Low frequency (1-Hz), right prefrontal repetitive transcranial magnetic stimulation (rTMS) compared with venlafaxine ER in the treatment of resistant depression: A doubleblind, single-centre, randomized study. Journal of Affective Disorders. 2009;118(1-3):94-100.

46. Blumberger DM, Mulsant BH, Fitzgerald PB, et al. A randomized double-blind sham-controlled comparison of unilateral and bilateral repetitive transcranial magnetic stimulation for treatment-resistant major depression. The World Journal of Biological Psychiatry. 2012;13(6):423-435.

47. Brakemeier E-L, Luborzewski A, Danker-Hopfe H, Kathmann N, Bajbouj M. Positive predictors for antidepressive response to prefrontal repetitive transcranial magnetic stimulation (rTMS). Journal of Psychiatric Research. 2007;41(5):395-403.

48. Brakemeier E-L, Wilbertz G, Rodax S, et al. Patterns of response to repetitive transcranial magnetic stimulation (rTMS) in major depression: Replication study in drug-free patients. Journal of Affective Disorders. 2008;108(1-2):59-70.

49. Chen S-J, Chang C-H, Tsai H-C, Chen S-T, Lin CCH. Superior antidepressant effect occurring 1 month after rTMS: Add-on rTMS for subjects with medication-resistant depression. Neuropsychiatric Disease and Treatment. 2013;9.

50. Cohen RB, Boggio PS, Fregni F. Risk factors for relapse after remission with repetitive transcranial magnetic stimulation for the treatment of depression. Depression and Anxiety. 2009;26(7):682-688.

51. Dell'osso B, Altamura AC. Augmentative transcranial magnetic stimulation (TMS) combined with brain navigation in drug-resistant rapid cycling bipolar depression: a case report of acute and maintenance efficacy. The World Journal of Biological Psychiatry: The Official Journal of The World Federation of Societies of Biological Psychiatry. 2009;10(4 Pt 2):673-676. 
52. Fitzgerald PB, Hoy KE, Herring SE, et al. A double blind randomized trial of unilateral left and bilateral prefrontal cortex transcranial magnetic stimulation in treatment resistant major depression. Journal of Affective Disorders. 2012;139(2):193-198.

53. Furtado CP, Hoy KE, Maller JJ, Savage G, Daskalakis ZJ, Fitzgerald PB. Cognitive and volumetric predictors of response to repetitive transcranial magnetic stimulation (rTMS) - a prospective follow-up study. Psychiatry Research. 2012;202(1):12-19.

54. Galletly C, Gill S, Clarke P, Burton C, Fitzgerald PB. A randomized trial comparing repetitive transcranial magnetic stimulation given 3 days/week and 5 days/week for the treatment of major depression: Is efficacy related to the duration of treatment or the number of treatments? Psychological Medicine. 2012;42(5):981-988.

55. George MS, Lisanby SH, Avery D, et al. Daily left prefrontal transcranial magnetic stimulation therapy for major depressive disorder: a sham-controlled randomized trial. Archives of General Psychiatry. 2010;67(5):507-516.

56. Hadley D, Anderson BS, Borckardt JJ, et al. Safety, tolerability, and effectiveness of high doses of adjunctive daily left prefrontal repetitive transcranial magnetic stimulation for treatment-resistant depression in a clinical setting. The Journal of ECT. 2011;27(1): $18-25$.

57. He ML, Gu ZT, Wang XY, Shi HP. Treatment of depression using sleep electroencephalogram modulated repetitive transcranial magnetic stimulation. Chinese Medical Journal. 2011;124(12):1779-1783.

58. Herbsman T, Avery D, Ramsey D, et al. More lateral and anterior prefrontal coil location is associated with better repetitive transcranial magnetic stimulation antidepressant response. Biological Psychiatry. 2009;66(5):509-515.

59. Hernández-Ribas R, Deus J, Pujol J, et al. Identifying brain imaging correlates of clinical response to repetitive transcranial magnetic stimulation (rTMS) in major depression. Brain Stimulation. 2013;6(1):54-61.

60. Herwig U, Cardenas-Morales L, Connemann BJ, KammerT, SchönfeldtLecuona C. Sham or real-post hoc estimation of stimulation condition in a randomized transcranial magnetic stimulation trial. Neuroscience Letters. 2010;471(1):30-33.

61. Hoeppner J, Padberg F, Domes G, et al. Influence of repetitive transcranial magnetic stimulation on psychomotor symptoms in major depression. European Archives of Psychiatry and Clinical Neuroscience. 2010;260(3):197-202.

62. Hoy KE, Segrave RA, Daskalakis ZJ, Fitzgerald PB. Investigating the relationship between cognitive change and antidepressant response following rTMS: A large scale retrospective study. Brain Stimulation. 2012;5(4):539-546.

63. Huang C-C, Wei IH, Chou Y-H, Su T-P. Effect of age, gender, menopausal status, and ovarian hormonal level on rTMS in treatmentresistant depression. Psychoneuroendocrinology. 2008;33(6): $821-831$.

64. Huang Ml, Luo By, $\mathrm{Hu} \mathrm{Jb}$, et al. Repetitive transcranial magnetic stimulation in combination with citalopram in young patients with firstepisode major depressive disorder: A double-blind, randomized, shamcontrolled trial. Australian and New Zealand Journal of Psychiatry. 2012;46(3):257-264.

65. Jakob F, Brakemeier E-L, Schommer NC, et al. Ultrahigh frequency repetitive transcranial magnetic stimulation in unipolar depression. Journal of Clinical Psychopharmacology. 2008;28(4):474-476.

66. Kozel FA, Johnson KA, Nahas Z, et al. Fractional anisotropy changes after several weeks of daily left high-frequency repetitive transcranial magnetic stimulation of the prefrontal cortex to treat major depression. The Journal of ECT. 2011;27(1):5-10.

67. Kreuzer PM, Langguth B, Schecklmann M, Eichhammer P, Hajak G, Landgrebe $M$. Can repetitive transcranial magnetic stimulation prolong the antidepressant effects of sleep deprivation? Brain Stimulation. 2012;5(2):141-147.

68. Lingeswaran A. Repetitive Transcranial Magnetic Stimulation in the Treatment of depression: A Randomized, Double-blind, Placebo-controlled Trial. Indian Journal of Psychological Medicine. 2011;33(1):35-44
69. Lisanby SH, Husain MM, Rosenquist PB, et al. Daily left prefrontal repetitive transcranial magnetic stimulation in the acute treatment of major depression: clinical predictors of outcome in a multisite, randomized controlled clinical trial. Neuropsychopharmacology. 2009;34(2):522-534.

70. Myczkowski ML, Dias AM, Luvisotto T, et al. Effects of repetitive transcranial magnetic stimulation on clinical, social, and cognitive performance in postpartum depression. Neuropsychiatric Disease and Treatment. 2012;8:491-500.

71. Nongpiur A, Sinha VK, Praharaj SK, Goyal N. Theta-patterned, frequency-modulated priming stimulation enhances low-frequency, right prefrontal cortex repetitive transcranial magnetic stimulation (rTMS) in depression: A randomized, sham-controlled study. The Journal of Neuropsychiatry and Clinical Neurosciences. 2011;23(3):348-357.

72. Paillère Martinot M-L, Galinowski A, Ringuenet D, et al. Influence of prefrontal target region on the efficacy of repetitive transcranial magnetic stimulation in patients with medication-resistant depression: A [18F]-fluorodeoxyglucose PET and MRI study. International Journal of Neuropsychopharmacology. 2010;13(1):45-59.

73. Pallanti S, Bernardi S, Di Rollo A, Antonini S, Quercioli L. Unilateral low frequency versus sequential bilateral repetitive transcranial magnetic stimulation: is simpler better for treatment of resistant depression? Neuroscience. 2010;167(2):323-328.

74. Peng H, Zheng H, Li L, et al. High-frequency rTMS treatment increases white matter FA in the left middle frontal gyrus in young patients with treatment-resistant depression. Journal of Affective Disorders. 2012;136:249-257.

75. Ray S, Nizamie SH, Akhtar S, Praharaj SK, Mishra BR, Zia-ul-Haq M. Efficacy of adjunctive high frequency repetitive transcranial magnetic stimulation of left prefrontal cortex in depression: A randomized sham controlled study. Journal of Affective Disorders. 2011;128(1-2):153-159.

76. Rosenquist PB, Krystal A, Heart KL, Demitrack MA, Vaughn McCall W. Left dorsolateral prefrontal transcranial magnetic stimulation (TMS): sleep factor changes during treatment in patients with pharmacoresistant major depressive disorder. Psychiatry Research. 2013;205(1-2):67-73

77. Schrijvers DL, Baeken C, De Raedt R, Sabbe BGC. The impact of high-frequency repetitive transcranial magnetic stimulation on fine motor functions in medication-resistant major depression. Neuropsychobiology. 2012;66(4):252-258.

78. Schutter DJLG, Laman DM, van Honk J, Vergouwen AC, Koerselman GF. Partial clinical response to 2 weeks of $2 \mathrm{~Hz}$ repetitive transcranial magnetic stimulation to the right parietal cortex in depression. International Journal of Neuropsychopharmacology. 2009;12(5): 643-650.

79. Schutter DJLG, van Honk J, Laman M, Vergouwen AC, Koerselman F. Increased sensitivity for angry faces in depressive disorder following 2 weeks of 2-Hz repetitive transcranial magnetic stimulation to the right parietal cortex. International Journal of Neuropsychopharmacology. 2010;13(9):1155-1161.

80. Simpson KN, Welch MJ, Kozel FA, Demitrack MA, Nahas Z. Costeffectiveness of transcranial magnetic stimulation in the treatment of major depression: a health economics analysis. Advances In Therapy. 2009;26(3):346-368.

81. Spampinato C, Aguglia E, Concerto C, et al. Transcranial magnetic stimulation in the assessment of motor cortex excitability and treatment of drug-resistant major depression. IEEE Transactions on Neural Systems and Rehabilitation Engineering. 2013;21(3): 391-403.

82. Speer AM, Benson BE, Kimbrell TK, et al. Opposite effects of high and low frequency rTMS on mood in depressed patients: Relationship to baseline cerebral activity on PET. Journal of Affective Disorders. 2009;115(3):386-394.

83. Speer AM, Wassermann EM, Benson BE, Herscovitch P, Post RM. Antidepressant Efficacy of High and Low Frequency rTMS at $110 \%$ of Motor Threshold versus Sham Stimulation over Left Prefrontal Cortex. Brain Stimulation. 2013. 
84. Tamas RL, Menkes D, El-Mallakh RS. Stimulating research: a prospective, randomized, double-blind, sham-controlled study of slow transcranial magnetic stimulation in depressed bipolar patients. The Journal of Neuropsychiatry and Clinical Neurosciences. 2007;19(2):198-199.

85. Triggs WJ, Ricciuti N, Ward HE, et al. Right and left dorsolateral pre-frontal rTMS treatment of refractory depression: A randomized, sham-controlled trial. Psychiatry Research. 2010;178(3):467-474.

86. Trojak B, Chauvet-Gelinier J-C, Vergès B, Bonin B. Significant increase in plasma thyroid-stimulating hormone during low-frequency repetitive transcranial magnetic stimulation. The Journal of Neuropsychiatry and Clinical Neurosciences. 2011;23(1):E12-E12.

87. Ullrich H, Kranaster L, Sigges E, Andrich J, Sartorius A. Ultra-highfrequency left prefrontal transcranial magnetic stimulation as augmentation in severely ill patients with depression: a naturalistic sham-controlled, double-blind, randomized trial. Neuropsychobiology. 2012;66(3):141-148.
88. Zarkowski P, Navarro R, Pavlicova M, George MS, Avery D. The effect of daily prefrontal repetitive transcranial magnetic stimulation over several weeks on resting motor threshold. Brain Stimulation. 2009;2(3):163-167.

89. Zheng H-r, Li L-j, Zhang L. Treatment of rTMS on young patients with intractable depression. Chinese Journal of Clinical Psychology. 2010;18(1):44-46.

90. Zheng $\mathrm{H}$, Zhang L, Li L, et al. High-frequency rTMS treatment increases left prefrontal myo-inositol in young patients with treatment-resistant depression. Progress in Neuro-Psychopharmacology and Biological Psychiatry. 2010;34(7):1189-1195.

\section{Publish your work in this journal}

Neuropsychiatric Disease and Treatment is an international, peerreviewed journal of clinical therapeutics and pharmacology focusing on concise rapid reporting of clinical or pre-clinical studies on a range of neuropsychiatric and neurological disorders. This journal is indexed on PubMed Central, the 'PsycINFO' database and CAS.
The manuscript management system is completely online and includes a very quick and fair peer-review system, which is all easy to use. Visit http://www.dovepress.com/testimonials.php to read real quotes from published authors.

Submit your manuscript here: http://www.dovepress.com/neuropsychiatric-disease-and-treatment-journal 